\title{
LA NUEVA HISTORIA Y SUS PREDECESORES*
}

Gonzalo Cataño

* DOI: https://doi.org/10.18601/01245996.v20n39.06 Ponencia presentada en la plenaria del XVIII Congreso Colombiano de Historia dedicado a la memoria de Jaime Jaramillo Uribe, Medellín, 10-13 de octubre de 2017. Agradezco la atenta lectura y las correcciones y mejoras sugeridas por los profesores Juan Camilo Rodríguez y Mauricio Pérez Salazar de la Universidad Externado de Colombia. Recepción: 23-08-2017, modificación final: 23-012018, aceptación: 11-05-2018. Sugerencia de citación: Cataño, G. (2018). La nueva historia y sus predecesores. Revista de Economía Institucional, 20(39), 119-158.

a Sociólogo y doctor en Sociología del Derecho, profesor-investigador, Universidad Externado de Colombia, Bogotá, Colombia, [anomia45@outlook. com]. 


\section{La Nueva Historia y sus predecesores}

Resumen. Este ensayo resume las características de la Nueva Historia, el movimiento historiográfico que dejó atrás la investigación tradicional del pasado en Colombia. Describe sus antecedentes a finales del siglo XIX, cuando se discutió el proyecto de hacer de la historia una disciplina científica. Menciona sus investigaciones, sus logros y sus adalides. Señala, además, las limitaciones de la Nueva Historia, cuyo énfasis en los fundamentos económicos de la sociedad y en el papel de las instituciones tendió a oscurecer el papel de las personalidades y la presencia de los "imaginarios". Así mismo, desdibujó el peso de las ideas, las actitudes y los valores; de la religión, la cultura y los modos de vida.

Palabras clave: historia científica, historia y sociología, positivismo, archivos, observación y medición, memoria; JEL: B52, Z10.

\section{The 'New History' and its predecessors}

Abstract. This essay summarizes the characteristics of the so-called New History, the historiographical movement that left behind the traditional research of the past in Colombia. It describes its background at the end of the 19 th century, when the project to make history a scientific discipline was discussed. It mentions its research, achievements and champions. It also points out the limitations of the New History, whose emphasis on the economic foundations of society and on the role of institutions tended to obscure the role of personalities and the presence of "imaginaries". Likewise, it blurred the weight of ideas, attitudes and values; of religion, culture and ways of life.

Keywords: Scientific history, history and sociology, positivism, archives, observation and measurement, memory; JEL: B52, Z10.

\section{A Nova História e seus predecessores}

Resumo. Este ensaio resume as característica da Nova História, o movimento historiográfico que deixou para trás a pesquisa tradicional do passado na Colômbia. Descreve seus antecedentes no final do século XIX, quando se discutiu o projeto de fazer da história uma disciplina científica. Menciona suas pesquisas, conquistas e defensores. Além disso, indica as limitações da Nova História, cuja ênfase nos fundamentos econômicos da sociedade e no papel das instituições tendeu a escurecer o papel das personalidades e a presença dos "imaginários". Ainda, desfez o peso das ideias, das atitudes e dos valores, bem como da religião, da cultura e dos modos de vida.

Palavras-chaves: história científica, história e sociologia, positivismo, arquivos, observação e medição, memória; JEL: B52, Z10. 
En un pasaje de La democracia en América de 1840, Tocqueville aludió a dos estilos de hacer historia: el de los siglos aristocráticos y el de los siglos democráticos (Tocqueville, 1989, pp.118-122). Hoy en día estos vocablos han perdido fuerza, pero no la materia que les dio impulso. En vez de historiadores aristocráticos y democráticos se podría decir historiadores característicos de las sociedades tradicionales e historiadores propios de las sociedades modernas.

Según Tocqueville, los historiadores de las sociedades tradicionales son dados a exponer los acontecimientos del pasado como resultado de la voluntad de unos pocos hombres o del carácter de ciertos conductores políticos. Concentran la atención en un reducido número de actores y los sitúan en el primer plano de la escena histórica. Ante sus ojos, "el paso de un hombre les parece romper la trama de la historia”. Son, además, propensos a insistir en las causas pequeñas de la evolución de los pueblos con menoscabo de las de mayor peso. Se los ve inclinados a interpretar las revoluciones, y demás manifestaciones del cambio social por accidentes menores, "floreros de Llorente", con manifiesto descuido de los procesos más significativos vinculados con la estructura social. Ese ligero y voluntarioso recurrir a rasgos volátiles de ocasión que se cree ponen en movimiento a príncipes, ejércitos y demás fuerzas sociales es el que Pascal estampó en la recurrida sentencia: "La nariz de Cleopatra, de haber sido más corta, habría cambiado la faz de la tierra" (2012, p. 471).

Los historiadores de las sociedades modernas revelan tendencias opuestas. No confieren mayor influencia a los individuos; los consideran mera expresión de las condiciones generales de la sociedad. Para ellos, los acontecimientos -grandes y pequeños- están inmersos en una cadena estrecha y necesaria. Se inclinan a negar a las naciones la capacidad de decidir por sí mismas y a discutirles la eventualidad de hacer lo que no han hecho. A cada suceso le atribuyen una gran causa reguladora, de la cual derivan un sistema que une las particularidades con el todo. Piensan que el movimiento de los pueblos no es intencional ni consciente y que las sociedades obedecen, sin saberlo, a fuerzas superiores que las dominan. A fin de justificar esta postura, el historiador recurre a nociones borrosas como "naturaleza de las razas", "constitución física de un pueblo", "alma de las civilizaciones", "espíritu de los tiempos", etc. Este enfoque somete a las sociedades a un destino inflexible, hurtándoles la posibilidad de modificar su sino, empujando al género humano a seguir una senda prescrita que 
a menudo termina en un esquema de etapas históricas que se suceden irremediablemente en una dirección dominada por la Providencia.

Tocqueville llamó doctrina de la fatalidad a estos énfasis: la postura historiográfica a la que no le basta mostrar cómo sucedieron los hechos, sino que además enseña que las cosas no habrían podido suceder de otra manera. Cuando una nación ha llegado a cierto punto de su historia conceptúan que estuvo obligada a hacerlo dado que no tuvo oportunidad de tomar una ruta diferente. Es la muerte del libre albedrío, de toda elección que podría subvertir y dejar atrás los condicionamientos externos de una época.

Tocqueville expuso su tipología en los albores de la historiografía moderna, que buscaba afirmarse como una disciplina con un instrumental de investigación preciso y confiable. Eran los años treinta del siglo XIX cuando la historiografía con ímpetu científico apenas daba los primeros pasos. Tocqueville reaccionó y tomó posición al respecto. No aceptaba los condicionamientos asfixiantes y opresivos. "Creo que en casi todos los instantes de su existencia, las naciones, como los hombres, son libres de modificar su destino" (Tocqueville, 1989, p. 121). Y agregó:

En cuanto a mí, pienso que no hay época en la que no se deba atribuir una parte de los acontecimientos de este mundo a hechos muy generales y otra a influencias muy particulares. Estas dos causas se encuentran siempre, solo difiere su relación. Los hechos generales explican más cosas en los siglos democráticos que en los siglos aristocráticos, y las influencias particulares, menos. En las épocas de aristocracia es al contrario; las influencias particulares son más fuertes y las causas generales son más débiles, a menos que se considere como una causa general el hecho mismo de la desigualdad de condiciones, que permite a algunos individuos contrariar las tendencias naturales de todos los demás. (ibíd., p. 120)

Tocqueville no se olvidaba por lo demás de la huella de los grandes hombres. Sabía que la suerte de un pueblo se podía ver en ocasiones comprometida por la influencia de una gran personalidad, como fue el caso de Napoleón que observó de manera directa. Tampoco desdeñaba los accidentes inesperados - magnos o pequeños- como las plagas, los desastres naturales, la derrota en el campo de batalla o la irrupción de una nación poderosa en un territorio pobre y atrasado bajo la modalidad de anexión, descubrimiento o conquista. Él mismo puso en acción años después su manera de hacer historia en un libro notable por su tratamiento de la materia, El Antiguo Régimen y la Revolución, donde ofreció, con furor analítico y primor de estilo, un novedoso retrato de la sociedad francesa anterior a 1789. "Profundo 
escritor [de] maestra mano" lo llamó Rafael Núñez al pasar revista de esta obra en 1883 (1945, I (2), p. 118) ${ }^{1}$.

La Nueva Historia surgió en Colombia del legado de los historiadores modernos, esto es, de los investigadores europeos del siglo XIX y de la primera mitad del XX que afirmaron la disciplina como un campo legítimo de investigación. La de Ranke y su escuela en Alemania; la de Macaulay, Renán y Taine en Inglaterra y Francia; la de Pirenne en Bélgica; la de Huizinga en los Países Bajos y la de los Annales en Francia. Siguiendo estos ejemplos elaboró su programa de trabajo. Quería superar el biografismo asociado con la exaltación y encomio de personalidades del pasado, así como la descripción de hechos y casos aislados que apenas se diferenciaban de la crónica y el relato literariamente orientados. Con la aplicada consulta de archivos y el auxilio analítico de las ciencias sociales, examinó la vida económica, la demografía, las creencias, los conflictos sociales, la estratificación social y las formas de dominación. Surgió en los años sesenta del siglo $\mathrm{XX}$ y se propagó con éxito por la década siguiente para afirmarse en los ochenta como el patrón dominante de la investigación histórica nacional. Su manifiesto intelectual lo constituyó la salida del primer número del Anuario Colombiano de Historia Social y de la Cultura en 1963, bajo la dirección de Jaime Jaramillo Uribe, esfuerzo que se vio reforzado el año siguiente con la publicación de El pensamiento colombiano en el siglo XIX. Fueron además los días de la creación de la Sección de Historia de Colombia y América en la Facultad de Filosofía y Letras de la Universidad Nacional de Colombia, programa que en 1965 se independizó de dicha facultad para afirmarse como Departamento de Historia, donde se formaron los primeros historiadores profesionales del país.

Con estos logros Jaramillo afianzó su liderazgo. Enseñaba historia y la hacía. Su mente se movía cómodamente por el mundo colonial y por el siglo XIX. Sobre cada uno de estos períodos escribió ensayos

${ }^{1}$ La democracia en América se compone de dos volúmenes. El primero salió en París en 1835 y el segundo cinco años después. La traducción castellana del primer volumen, bajo el título De la democracia en la América del Norte, a cargo del español D. A. Sánchez de Bustamante, se publicó en Francia en 1837 por la casa Rosa. El segundo volumen, en versión del bogotano Leopoldo Borda, se imprimió en París en 1842 por la Librería de don Vicente Salvá (de allí que llevara la advertencia, “continuación”). E1 libro circuló ampliamente en el país. Recordemos, por lo demás, que Efraín -en Mariatenía una copia de La democracia en su biblioteca (ver Isaacs, 2005, p. 101). 
de sabor monográfico con abundante material de archivo. Leía en francés, inglés y alemán, y estaba familiarizado con el derecho, la filosofía y la sociología, lo mismo que con los usos de la economía, la demografía, la antropología y la geografía. Esto le facilitó un conocimiento de las contribuciones francesas, inglesas y alemanas a la historia y demás ciencias de la cultura. Junto a ello meditó sobre el contenido y alcance de la historia para conferirle sentido a su labor, orientar el trabajo de sus alumnos y marcar las diferencias con la historiografía que intentaba dejar atrás. A estas labores sumó las fatigas administrativas del Departamento de Historia en un momento en que la universidad colombiana se transformaba en una institución que intentaba combinar la docencia con la indagación empírica. Sabía que profesor que no se comprometiera con la investigación carecía de legitimidad para exigirla a sus estudiantes. El ejemplo debía comenzar por casa y no en la morada de los vecinos que cultivaban con éxito otras ciencias.

Como lo evidencia el epígrafe de este ensayo, Jaramillo era consciente de su liderazgo y de su papel en la renovación de los estudios históricos en el país. Pensaba que la historia era un brazo más de las ciencias sociales, razón por la cual debía atender las demandas del espíritu científico. Es una ciencia fáctica, de realidades, y su método no es radicalmente distinto al seguido por las disciplinas que estudian el mundo físico y natural. Observa hechos, establece nexos entre ellos y postula explicaciones, relaciones de causalidad. Trabaja con marcos de referencia, con teorías que le sirven para delimitar el infinito mundo de lo real, valorar los datos y conferirle sentido a la información. A pesar de que trabaja con experiencias singulares no le es extraña la generalización. El analista debe adentrarse en lo particular considerando lo general y codearse con lo abstracto cuando explora lo concreto. Cuando estudió la esclavitud en la Nueva Granada sabía que era un caso más de una sujeción extrema que atravesó la vida de Grecia, Roma, Brasil y Estados Unidos. Sospechaba que si se desatienden estas demandas de teoría y método la historia está en peligro de caer en la crónica estéril o en el glacial registro de sucesos sin brío analítico. Este fue el marco dentro del cual se desenvolvió su obra y por extensión la de la Nueva Historia.

¿Contra qué y quién luchaba la Nueva Historia? Contra el relato fácil e incontrolado del pasado difundido en el formato del ensayo de alguna extensión que atendía más a la elegancia de la exposición que al desarrollo controlado, austero y sistemático del tema de estudio. Su expresión más acabada se encontraba en lo que uno de sus 
miembros llamó la "modalidad académica" de hacer historia, típico - mas no exclusiva- de los miembros de la Academia Colombiana de Historia, una institución sostenida por el Estado (Melo, 1979, pp. 29-33). Su patrón dominante se caracterizaba por el uso piadoso de la documentación y por la publicación de libros y ensayos colmados de citas in extenso unidas por rápidas y ocasionales intervenciones del autor, que generalmente no agregaban mayor ilustración a lo que abrazan las dilatadas comillas. Por ausencia de familiaridad con las ciencias sociales, sus textos carecían de un marco de referencia que situara el tema elegido en el conjunto de la organización social. Sus autores eran muy dados a privilegiar las genealogías y las biografías encomiásticas dirigidas a ennoblecer familias o héroes de la nacionalidad para explotar su carácter ejemplar y moralizante. Estudiaban una personalidad creyendo que con ella retrataban el conjunto de la sociedad. Con Saavedra Fajardo (1988, p. 5) pensaban que del gobierno de uno dependía la salud de todos. Eran por lo demás muy dados a subrayar ciertos períodos -Descubrimiento, Conquista e Independencia- que facilitaban la honra de los libertadores o el entusiasmo por algunos aspectos de la cultura como el idioma, la "raza" y la religión heredadas de España, la madre patria. Desde su fundación en 1902 la Academia había hecho suyo el lema del bardo italiano de la Storia universale: "no ha muerto ni morirá una nación que recuerda sus héroes y busca en un pasado glorioso fuerzas para resistir al envilecimiento" 2 .

A estos rasgos se sumaban las condiciones materiales de los historiadores. No existía la carrera profesional del historiador. No había posibilidad de vivir de la historia para impulsarla. Los émulos colombianos de Heródoto eran, de alguna manera, unos titanes. Cultivaban la historia a tiempo parcial, en las holganzas que les consentían los deberes del modus vivendi: la política, los negocios, el periodismo, la docencia a tiempo parcial, el desempeño profesional o una combinación de unos y otros. Estas dificultades hicieron que por muchos años la historia fuera en el país una superestructura que carecía de los fundamentos materiales de su realización, situación que dejó su huella en la fragilidad los trabajos de los académicos y demás entusiastas en las tribulaciones de los tiempos antiguos. La investigación, con visitas ocasionales a los archivos o a los centros de documentación públicos, la desarrollaban preferentemente en sus gabinetes junto a

${ }^{2}$ Palabras de Cesare Cantù recordadas por Eduardo Posada, primer presidente de la Academia Colombiana de Historia, en su discurso de posesión en octubre de 1902 (1908, p. 80). 
las bibliotecas hogareñas, muchas de ellas de gran tamaño dadas las limitaciones de las bibliotecas públicas y de las universidades, siempre escasas de recursos para actualizar sus fondos bibliográficos. Esto hizo que con frecuencia sus productos fueran el resultado de meras reelaboraciones -apostillas, interpretaciones y comentarios- de la bibliografía secundaria que poco o nada añadían al saber anterior. Esta vía abrió a muchos aficionados el fácil camino del charlatanismo donde se abandonaba todo rigor fáctico y analítico para entregarse al relato de amenidades de los tiempos oscuros y ganar el favor de los lectores. A ello se unía la callada exigencia de los medios en los cuales los diletantes solían difundir sus escritos, diarios y revistas de énfasis literario dirigidas al gran público, poco tolerantes con los rigores de la ciencia y los fastidios de la erudición ${ }^{3}$.

La Nueva Historia puso en cuestión esta forma de hacer historia que hoy en día sobrevive gracias a la subvención de la Academia por parte del Estado, corporación integrada por un grupo de animadores del pasado muy dados a las efemérides de almanaque. Uno de sus miembros más conspicuos, el secretario de la Academia, Roberto Velandia, antiguo funcionario público, se encargó de dar respuesta a los reclamos de los innovadores. En una extensa crónica del centenario de la Academia escribió:

[Los académicos no debemos] desconocer a otros historiadores, independientes, militantes de otras doctrinas, enfilados en campamento aparte, que le han dado a la historia colombiana una interpretación materialista, argumentada más en la prevalencia de factores económicos y encarnada más en la colectividad que en los individuos, quienes han querido despojarla de lo más bello que tiene nuestra historia: idealismo, heroísmo, sentimiento de patria y nacionalidad. De ellos son representativos Jaime Jaramillo Uribe, Germán Colmenares, Jorge Orlando Melo, Álvaro Tirado Mejía, Rafael Gutiérrez Girardot, Hermes Tovar. (Velandia, 2001, p. 15) ${ }^{4}$

${ }^{3}$ Esta caracterización de la Academia, que puede terminar en caricatura, no debe llevar a olvidar, sin embargo, la labor de calidad empírica y argumentativa de algunos de sus miembros, como es el caso de los trabajos de Horacio Rodríguez Plata, Luis Martínez Delgado, Pablo E. Cárdenas Acosta, Guillermo Hernández de Alba, Gustavo Arboleda, Joaquín Tamayo y Gabriel Giraldo Jaramillo. Todos ellos tenían lo que Lytton Strachey (1997, p. 163) llamaba capacidad para asimilar hechos, energía para enunciarlos y un punto de vista para explicarlos.

${ }^{4}$ La inclusión del crítico de la cultura Gutiérrez Girardot en esta lista sorprende a los miembros de la guilda historiográfica. Un balance de la Academia Colombiana de Historia se encuentra en Betancourt (2007, cap. II). 
Las demandas de Jaramillo y de sus alumnos no eran sin embargo tan "nuevas" como ellos creían. Como disciplina, la historia llevaba en el país un largo ejercicio de afirmación y prueba. Varios investigadores de años anteriores habían planteado inquietudes semejantes con resultados estimables. En 1962, un año antes de los pronunciamientos de Jaramillo, el etnohistoriador Juan Friede promovió una vivaz controversia en el seno de la Academia, encerrada, a su juicio, en "un ambiente un tanto trasnochado" 5 . En una de sus sesiones leyó el trabajo "La investigación histórica en Colombia”, donde planteó la necesidad de emprender cambios radicales en el oficio (Friede, 1964a). Allí apuntó que no existía en el medio una preparación profesional del historiador y que su tarea la hacía, en esos días, "cualquiera que tenga suficiente ocio o entradas económicas que se lo permitan". Muchos aficionados se adentraban en la disciplina por tradición familiar o por conveniencias políticas o ideológicas a fin de legitimar las decisiones de un partido político (el liberal o el conservador) o exaltar un linaje de grandes logros en la Colonia o en el siglo XIX. Para este fin echaban mano de la historia heroica, de la visión que exagera el papel de ciertos nombres sin atender las fuerzas sociales que nutren su cometido. Esto hacía que hubiese mucha improvisación y que sus obras, por su estilo y planteamiento, pertenecieran más al género literario que al histórico.

En un segundo trabajo, "La investigación histórica" (Friede, 1964b), endureció su crítica y fue más explícito. "La historiografía americana ha descuidado el estudio de la influencia que ejercen los factores socioeconómicos en la evolución de nuestro mundo". Al subrayar la acción de ciertos individuos se tiende "a convertir la historia en una sucesión de biografías", que muchas veces se tratan de manera subjetiva cuando el historiador tiene afinidades personales con su "héroe": vínculos de familia, militancia en la misma facción política, identificación con una corriente ideológica o subordinación a una misma esfera de intereses materiales o espirituales. Ante estos énfasis se debe tornar al pueblo, a la población anónima que sustenta la marcha general de la sociedad. Para su tratamiento adecuado el historiador debe hacerse a las contribuciones de las ciencias sociales, como la sociología, disciplina que no solo ha penetrado en la historia política, económica e ideológica de la comunidad, sino también en los terrenos del arte y de la literatu-

5 Carta de Juan Friede a Luis Duque Gómez del 24 de marzo de 1962, citada por Rueda (2008, p. 342). 
ra. Esta dirección mostraría que los líderes no actúan en el vacío sino en medio de grupos en tensión y de estructuras materiales y afectivas sobre las cuales el paladín de turno desea dejar su huella. Por ello recomendó estudiar una serie de temas más amplios y de mayor significación:

E1 desarrollo demográfico de un pueblo; su estructura social; la producción y consumo de bienes materiales; el movimiento y el empleo del capital nacional y extranjero; el reparto de la propiedad y del ingreso nacionales; el carácter del gobierno y el funcionamiento del aparato administrativo; el régimen tributario; el juego e influencia de los partidos políticos; el nivel cultural del pueblo y la persistencia o debilidad de sus tradiciones; el estado psicológico de las masas resultado de determinadas situaciones, etc., son elementos decisivos en la evolución de la sociedad. Pueden contribuir al mantenimiento de una situación dada y al rechazo de ideas y acciones inconformes o, por el contrario, originar una tensión social propicia a ellas, capaz de sacudir a la comunidad hasta sus más íntimas raíces. Son estos los elementos que determinan la efectividad de las acciones individuales y ningún historiador puede evadir la investigación de tan importantes aspectos sociales. (ibíd., p. 1585)

Las reacciones de la Academia no se hicieron esperar. Uno de sus miembros, el profesor de crítica histórica de la Pontificia Universidad Javeriana, Miguel Aguilera, creyó ver en "la hábil ponencia” del señor Friede una predilección por las "obras de penetración socialista" que lo sitúan en las fronteras "de lo que la ciencia moderna denomina materialismo histórico y dialéctica materialista" (Aguilera, 1962). Otro académico, el presbítero Rafael Gómez Hoyos (1964), no se quedó atrás. Siguiendo las enseñanzas de Toynbee y de Ortega y Gasset arguyó que todo proceso histórico se basa en los hombres creadores y en las minorías selectas que organizan y orientan a las masas. Agregó, además, que el énfasis socio-económico desconoce los aspectos culturales sin los cuales es imposible entender el pasado, perspectiva que en modo alguno debería asumir la Academia. Aceptarla sería convertir la historia "en simple sociología de determinada tendencia", como lo muestra la "aparatosa movilización de tesis revolucionarias" enunciadas por Friede en su artículo bajo la forma de recomendaciones. Y le recordó a su oponente que es difícil alcanzar el historiador perfecto, aquel que eventualmente reúna todas las cualidades ideales. Mientras llega -señaló-, el investigador corriente debe seguir aportando "con patriótico entusiasmo" los materiales para crear una base sólida de investigación, pues solo habrá "grandes historiadores cuando Dios se haya servido de concedérselos” al país. El presbítero terminó su réplica con una sugerencia: 
Sería conveniente que el debate terminara con una proposición en la cual la Academia, reafirmando su criterio tradicional, rechace los principios expuestos por el académico Friede, y manifieste por lo menos su extrañeza ante los ataques injustificados de que ha sido objeto por parte de uno de sus miembros de número. (ibíd., p. 993)

Es claro que la batalla por una historia moderna no era asunto fácil. Intereses de carácter ideológico, político y religioso se oponían a sus enfoques, a sus marcos de referencia y a sus formas de hacer ${ }^{6}$.

Pero muchas de las ideas debatidas en la Academia en 1962 ya habían sido ventiladas por algunos investigadores de los años cuarenta. Cuando el abogado Guillermo Hernández Rodríguez - con estancias formativas en ciencias sociales en Moscú, París y Nueva York durante los años veinte y treinta del siglo XX- se planteó su trabajo sobre el legado indígena en De los chibchas a la Colonia y a la República, abordó la información apartándose "del criterio anecdótico que ha tenido bastante predominio en Colombia, para sustituirlo por un examen histórico-sociológico auxiliado por la dialéctica materialista". Y añadió: "He tratado de que ningún patrioterismo prehistórico anime este libro" (Hernández, 1949, pp. 2 y 3). Sensible a las orientaciones de la sociología francesa, la de Durkheim y de su sobrino Marcel Mauss especialmente, estudió la comunidad chibcha y su desintegración social y cultural con la llegada de los españoles. Tras los tributos, la encomienda, la vida en las minas y la descomposición de los resguardos -el último amparo material de los indígenas-, el indio fue mudando en un sujeto que solo tenía en su haber la fuerza de trabajo que vendía a los dueños de la tierra, del comercio y de la incipiente industria que afloraba en pueblos y ciudades. Con el tiempo, una parte significativa de sus descendientes engrosó las primeras filas del proletariado que se asentó en los medios urbanos "con las pupilas todavía llenas de las verdes visiones de la campiña para diluirlas en el tono gris de las fábricas" (ibíd., p. 313).

Pero fue Luis E. Nieto Arteta quien planteó con más claridad los problemas de teoría y método. En confrontación directa con la

${ }^{6}$ Los textos de la controversia en el seno de la Academia fueron reproducidos por Rueda Enciso en su Juan Friede (2008, pp. 445-466). Ver igualmente Betancourt (2007, pp. 68-71) y Tirado (2014, p. 260). Friede se definía ante todo como un hombre de documentación metódica. En una ocasión le escribió a su amigo, el sociólogo Luis López de Mesa: "Mi cantera son los documentos que dejó el pasado colombiano en los archivos nacionales y extranjeros" (ibíd., p. 351). 
modalidad académica de aquellos años, abordó lo que llamó historia de oropel: fechas célebres, hechos gloriosos, registro de nombres ilustres, festejos del 20 de julio, aniversario de los líderes de la nacionalidad, exaltación de las batallas de Boyacá, Junín y Ayacucho, etc. (Cataño, 2013, p. 226). Era -a su juicio- una historia de pompa y esplendor, propensa al relato encomiástico y a la crónica animada y placentera que se confundía con la fábula y la leyenda. A esto se sumaba un marcado interés por la política, por la exaltación de personalidades y por la defensa de las acciones de una camarilla. "Conocido el Partido al cual pertenece el historiador se sabrá a ciencia cierta la actitud que optará ante ciertos hechos históricos”. Si el autor es de ideología liberal rechazará la intervención del general José María Obando en el asesinato del mariscal Antonio José de Sucre, si es conservador sustentará la tesis de que Obando fue el autor, o uno de los autores intelectuales, del abominable crimen (Nieto, 1978, pp. 218-219).

En respuesta a estos desvíos ofreció una obra analítica del desenvolvimiento de la nación, Economía y cultura en la historia de Colombia (1941), que marcó el rumbo de buena parte de los miembros de la Nueva Historia. Allí examinó la estructura social de la Colonia, las transformaciones económicas y sociales de mediados del siglo XIX y las tensiones políticas que antecedieron a la Regeneración, el período de la afirmación del Estado central. Su marco de referencia provenía del marxismo, tradición de pensamiento muy inclinada al estudio del surgimiento y desarrollo del capitalismo a partir de la desintegración del feudalismo. El libro era una historia de procesos sociales, no el relato de las tribulaciones de unos pocos regentes o el amable cuadro de los logros de una facción política.

A todo esto sumó una reflexión sobre el conocimiento histórico. Nieto fue el primero en el país que difundió con alguna extensión la querella entre ciencias del espíritu y ciencias naturales. Siguiendo las huellas de la reacción europea contra el positivismo, subrayó las diferencias entre la investigación de lo natural y la investigación de lo social. Con notable arrojo afirmó que los datos culturales eran singulares e irrepetibles, mientras que los naturales eran siempre iguales y susceptibles de generalización y de formulación mediante leyes. Además, al ser parte integrante de la sociedad, el analista se confunde con su objeto de estudio. A diferencia del científico natural que está en una posición de exterioridad anímica respecto de su tema, el investigador social hace parte de él. Estudia a hombres y mujeres en situaciones particulares cuando él mismo es uno de 
ellos o de ellas. Aquí el sujeto cognoscente y el objeto examinado se confunden.

En estas discusiones, Nieto dio especial tratamiento a la comprensión como estrategia de conocimiento. Mientras que en el reino de lo natural se puede medir, pesar y experimentar, en la esfera de lo social la estrategia de conocimiento es la comprensión, el reavivamiento interior de una vivencia del presente o del pasado para su mejor entendimiento. El investigador reúne, clasifica y pondera la información, y una vez que la ha hecho suya puede evaluar las acciones que desea explicar. Es la operación de buscar el sentido intencional que orienta la conducta en una situación determinada. Para Nieto y la corriente que le sirvió de aliento -Dilthey, Windelband y Rickert-, solo se comprenden las cosas que tienen sentido, esto es, cuando resultan del propósito de alcanzar un deseo, un valor buscado por individuos o grupos enteros que luchan por sus metas en el seno de un organismo social. Esta fue la afirmación de la comprensión como recurso gnoseológico central de los estudios históricos, que las generaciones siguientes hicieron suya con los debidos controles y adecuaciones ${ }^{7}$.

Los esfuerzos de Hernández Rodríguez y de Nieto Arteta fueron avalados por el solitario Luis Ospina Vásquez, autor de un libro, Industria y protección en Colombia (1955), que inauguró el campo de la historia económica. Hasta donde tenemos conocimiento, Ospina no teorizó sobre la esencia y contenido último de la historia, pero dejó su impronta en el campo. Tomando un período de ciento veinte años, 1810-1930, con previos trazos del periodo colonial, rastreó con datos tomados de diversas fuentes - periódicos y folletos sueltos sobre todo-el desarrollo de la manufactura junto a las cambiantes políticas estatales de librecambismo y proteccionismo. Estudió la relación entre el proceso de industrialización y las ideas y las prácticas en materia de amparo industrial. Esto lo llevó a concluir que la política económica fue un factor esencial en la evolución industrial del país, afirmación que lo condujo a subrayar el papel de las ideas - de las concepciones amparadas por el Estado- en los destinos de la economía nacional.

7 Una reseña de los problemas de teoría de la historia de la primera mitad del siglo XX no debería dejar de mencionar la Introducción al estudio de la filosofía de la historia del escritor, periodista y "filósofo" Emilio Cuervo Márquez. Redactada en Francia en los años treinta, se esperaba que esta Introducción trajera al país las novedades de la historiografía europea, pero su contenido resultó en un fiasco. En medio de una especulación sin freno, el autor se aventuró por las quebradizas sendas de la aparición de la vida en la tierra, por las singularidades del hombre prehistórico y por los nebulosos registros del origen del lenguaje, la religión y el alfabeto. 
En un segundo libro algo descuadernado, el Plan agrícola de 1963, resultado de unas conferencias que no quiso o no pudo corregir para alivio de sus lectores, expresó: "La historia de nuestras ideas político-económicas es la sucesión de sencillas recetas que aparecen bruscamente $[\mathrm{y}]$ se hacen aceptar por todos o por el grupo ideológico medio cuya influencia en la marcha de la vida pública es decisiva" (Ospina, 1963, p. 88) ${ }^{8}$.

Otro renovador de los estudios históricos, que desarrolló su obra por fuera de los marcos universitarios y gozó de gran fortuna, fue Indalecio Liévano Aguirre (1917-1982), un estricto contemporáneo de Jaramillo Uribe. Muy joven publicó una devota biografía de Rafael Núñez (1944) a la cual sumó seis años después una no menos piadosa biografía de Bolívar (1950). Su libro más representativo, Los grandes conflictos sociales y económicos de nuestra historia (1961), afirmó su postura historiográfica. Su centro fueron las luchas políticas, los motines, los alzamientos y las revoluciones. Donde los historiadores tradicionales vieron en la Colonia quietud y evolución pausada, Liévano levantó la bandera de la contradicción y la crisis. No fue un hombre de archivo, pero manejó la literatura secundaria y las fuentes impresas con imaginación y sorprendente soltura narrativa. Como los antropólogos de gabinete que jamás conocieron un pueblo primitivo, pero que tenían en su haber una teoría robusta para ver hechos de gran significado en los informes de campo de los colegas, Liévano fue capaz de extraer filones analíticos de las monografías de aquellos que pasaron meses enteros en los archivos. Estaba poseído por la noción de conflicto - por las ideas de competencia, disputa y rivalidades de intereses- que le permitió ver caudillos, sediciones y revueltas donde otros apenas veían animosidades y tensiones pasajeras. Lo guiaba un objetivo claro y simple que le confirió fuerza a su narración: exaltar a los humildes y vejar toda forma de opresión que favoreciera a los poderosos (Liévano, 1961, p. 11).

${ }^{8}$ En la polémica con Friede, el padre Gómez Hoyos se refirió de pasada, y $\sin$ mencionar nombres, a obras "como últimamente han aparecido, para desconcierto y sorpresa, por decir lo menos, de la opinión pública colombiana", donde el prisma del factor económico aparece como "criterio esencial y casi excluyente” (Gómez Hoyos, 1964, p. 989). No sabemos si el presbítero se refería a la segunda edición de Economía y cultura de Nieto Arteta, aparecida en 1962, o a Industria y protección de Ospina, dos obras analíticas ajenas a las delicias de la narrativa que hermanan la ciencia de Heródoto con el reino de las artes. 
Pero los historiadores de los años cuarenta y cincuenta del siglo XX también contaban con antecedentes. No partían de cero. Sus colegas de la generación anterior, la del novecientos, habían discutido cuestiones similares con respuestas parecidas. En los últimos años del siglo XIX llegaron a Colombia los ecos europeos de la historia científica. Macaulay, Renán y Taine eran muy populares, y textos generales de historia y manuales de metodología difundían en el país el mensaje de una historia rigurosa, precisa, objetiva, rica en datos y teóricamente relevante. La historia se hacía con documentos y su finalidad era exponer, analizar y cotejar hechos en medio del tejido que los une con otros procesos. Estos acentos manifestaban, además, que la historia no se reducía al estudio de las acciones de los grandes hombres ni al mero registro de acontecimientos que siguen la cronología (bistoire évènementielle). Esto era solo una manifestación superficial de los verdaderos procesos que nutren la historia. Detrás de ellos estaba el núcleo central, la causalidad estructural que animaba al conjunto de la sociedad, y para encontrarlos había que explorar los problemas de la muchedumbre, de la población que da forma a ese conjunto y crea la base donde se asientan la tradición y los modos de vida dominante de una nación'.

Esta novedad se difundió en periódicos y revistas de la época. En 1904, Sanín Cano escribió en la Revista Contemporánea que la historia no era solo la biografía de los "hombres representativos". También había que observar al hombre "promedial”, al ser que alumbra el término medio de las energías y aspiraciones de un pueblo, al mortal en cuya alma "se juntan las buenas y malas cualidades de una raza" (2006, p. 292). Aquí, "raza” denotaba la población de un país. En la misma dirección se manifestó Carlos Arturo Torres en una página de la encomiada Idola Fori de 1909. Allí declaró que había que superar la herolatría, la vía más segura para caer en la idolatría. Quien esto hace -señaló en una conferencia sobre la historiografía venezolana- no parece darse cuenta de la advertencia de Spencer: "la génesis del grande hombre depende de una larga serie de influencias complejas que ha producido la raza en medio de la cual aparece". Y agregó: con los ejemplos de Buckle, Taine, Seignobos, Altamira y Sorel, la historia, "que fue ayer un arte, conviértese hoy en una ciencia". No se olvidó de recordar que tras este impulso se

${ }_{9}$ Para un balance de las pretensiones de la historia científica, ver Isaiah Berlin, "E1 concepto de historia científica", recogido en Conceptos y categorias (1983).

Revista de Economía Institucional, vol. 20, N.o 39 , segundo Semestre/2oi 8, pp. Ii $9^{-1} 58$ 
encontraba la sociología, un saber sintético del mundo social que "aspira a hacer de la historia una verdadera ciencia natural, algo como el eslabón superior de la biología" (2001, I, p. 108 y II, pp. 383 y 386-387).

A todos ellos se había anticipado Rafael Núñez en sus Ensayos de crítica social de 1874. Allí escribió que en cuanto ser social el hombre también está sujeto a leyes que gobiernan su comportamiento. Atendiendo las enseñanzas de las ciencias naturales señaló que si de la sabandija hasta el sol todo el universo obedece a principios generales, “¿por qué el hombre en la más elevada de sus tendencias [1a sociabilidad] ha de ser la única excepción a la regla?". Contra lo que se cree, "la historia es una ciencia como la química y la botánica”, una disciplina que estudia los hechos antiguos atendiendo regularidades que fijan su desarrollo (Núñez, 1874, p. 166). Núñez ilustró su tesis alojada en el historicismo más severo -la historia obedece a leyes inflexibles-, subrayando las tendencias de su tiempo: el fortalecimiento de las formas republicanas y democráticas de gobierno ante las monarquías y demás gobiernos absolutos. Estos últimos subsisten, pero tienen sus días contados. A su lado surge de manera inexorable la emancipación de la persona humana con su respectiva consagración jurídica en la figura del habeas corpus (seguridad personal) y la liquidación de las desigualdades afincadas en antiguos privilegios. Florecen las clases medias y se exalta el universo de las “capas subalternas", aquellas que viven de la mendicidad o de trabajos subordinados, bajo la insignia de la libertad, la igualdad y los derechos del hombre. Es un "movimiento irresistible y ninguna forma de gobierno [será capaz de impedir] el cumplimiento de esta ley" (ibíd., pp. 169 y 171).

La idea de una historia científica llegó al país por múltiples vías. Ante todo por el libro de Rafael Altamira, La enseñanza de la historia (1895), que resumía las discusiones provenientes de Francia, Alemania, Italia y el Reino Unido. Después vino la popular Introduction aux études historiques (1898) de los franceses Charles V. Langlois y Charles Seignobos, el texto de metodología más popular de la época. Este libro recomendaba la lectura De l'bistoire considerérée comme science (1894) de Pierre Lacombe y discutía las contribuciones de dos influyentes libros de aquellos años: el robusto Lebrbuch der historischen Methode (1889) del alemán Ernst Bernheim y el informado y orientador volumen del escocés Robert Flint, History of the philosophy of history (1894), que cubría las contribuciones europeas del momento. Su nombre se hizo más familiar con la versión castellana, tomada del francés, de su Filosofía de la historia en Alemania (Madrid, s. f.), obra que estudiaba 
un largo período de la especulación histórica germana desde Leibniz hasta Hermann Lotze y el olvidado Conrad Hermann ${ }^{10}$.

E1 colombiano más entusiasta con la nueva ola historiográfica fue el militar, geógrafo e historiador Francisco Javier Vergara y Velasco, "Franjavier", nombre con el que lo conocieron sus contemporáneos para ahorrarse el pesado registro de la pila bautismal. Su Nueva geografía de Colombia (1888 y 1901) se destaca por la precisión de la información, el rigor en las observaciones y la minuciosa descripción de caminos, ríos, montañas y asentamientos humanos. Era un fanático de los datos y de los recursos de la estadística. "Eremita de la ciencia" lo llamó su amigo Marco Fidel Suárez (1958, I, p. 644). Esta pasión la trasladó a la historia, donde la geografía surgía como ciencia auxiliar que exploraba las condiciones del territorio por el cual circulaba la población de una nación con un pasado colmado de aspiraciones aupadas por luchas sociales y políticas.

En 1906 Franjavier publicó un ensayo titulado "Concepto moderno de la historia", basado en extractos y refundiciones de varios autores, entre los que descollaba la Introducción de Langlois y Seignobos (Vergara, 1906). Allí unió la historia con las demás ciencias sociales. Mientras que la historia narra y revive los acontecimientos singulares, la sociología y la economía con la ayuda de la filosofía los explican

${ }^{10}$ Hasta donde se tiene noticia, el Manual de Bernheim, el Lehrbuch, jamás se conoció en español. Su mensaje, difundido a través de la literatura secundaria, solo se hizo claro con el traslado de su sinopsis (la Einleitung de 1905) difundida tardíamente por la editorial Labor de Barcelona en 1937: Introducción al estudio de la historia, en versión del padre Pascual Galindo Romeo. La primera traducción de la Introducción a los estudios históricos de Langlois y Seignobos apareció en 1913 en las prensas de la afamada editorial Jorro de Madrid. La historia considerada como ciencia de Lacombe debió esperar más de medio siglo para su naturalización en los países de habla española. En 1948 la acogió la sucursal argentina de la casa Espasa-Calpe en su colección Historia y Filosofía de la Ciencia.

Muchos de los autores y enfoques teóricos y empíricos que sirvieron de guía a los nuevos historiadores nacionales se hallaban en el Curso de filosofía experimental de 1883, un libro de lecturas compilado por el educador César C. Guzmán que llevaba un prólogo del joven Ernst Röthlisberger. Allí había textos de Destutt de Tracy sobre la inteligencia, de Hippolyte Taine sobre la lógica de Stuart Mill, de Théodule Ribot sobre la psicología de Spencer y de Alexander Bain, de Claude Bernard sobre el raciocinio experimental, de Émile Ferrière sobre el darwinismo, de Ernst Haeckel sobre la descendencia del hombre, y uno del médico, físico y químico norteamericano George F. Barker sobre el problema de la vida. Guzmán, director de Instrucción Pública en 1872, interesado en los estudios gramaticales y autor de varios textos escolares, había vivido en Francia e Inglaterra y conocía las controversias intelectuales del momento. 
y les confieren generalidad. A sus ojos lo particular era de alguna manera una manifestación más de lo que le sucede a la humanidad en otros escenarios. En esta labor conjunta, el papel de la historia es la severidad de la información, el rigor en la búsqueda y fijación de los datos, esfuerzos que se alcanzan con la crítica permanente de las fuentes y el asiduo trabajo de archivo. Franjavier llenó estas demandas empíricas en su libro 1818 Guerra de independencia (1897), obra ejemplar en materia de asuntos fácticos y de prosa ajustada al contenido que deseaba exponer ${ }^{11}$.

Franjavier no estaba solo en esta tarea. Su contemporáneo, el jurista, educador y hacendista Diego Mendoza Pérez dio un impulso particular al proyecto científico. Sus trabajos no ostentaban el rigor empírico de los textos del geógrafo pero eran teóricamente más sólidos ${ }^{12}$. Fue el caso de su Ensayo sobre la evolución de la propiedad en Colombia (1897), un estudio histórico-sociológico que cubre el período colonial y gran parte del siglo XIX. Como sugiere el título de aliento spenceriano, Mendoza quería mostrar las transformaciones de una institución, la propiedad, a lo largo de varias centurias. Orientado por una idea muy cara al pensamiento liberal -la propiedad es la base de la libertad-, planteó una hipótesis que formuló con sorprendente claridad: "a medida que la tierra queda sometida al imperio de la apropiación individual y permanente, la libertad va creciendo".

Para dar cuerpo a estas ideas estudió cinco momentos del desenvolvimiento de la propiedad rural en el país: la encomienda, la

11 De la infatigable labor pedagógica de Franjavier se debe subrayar su traducción anotada de los capítulos sobre Colombia contenidos en la Géographie Universelle de Eliseo Reclus. Las aclaraciones a este texto crecieron tanto que el volumen Colombia de 1893 parecía un trabajo original. Sus "notas valen muchas veces más que lo anotado" le comunicó su amigo el explorador francés Jorge Brisson. Y el propio Reclus le manifestó: "En esta obra de colaboración vos sois en realidad el maestro, puesto que sabéis lo mejor" (Vergara y V., 1952, II, pp. 178 y 179). A estas tareas de difusión se deben sumar su traducción del opúsculo de Gabriel Monod, La historia (s. f.), uno de los manifiestos más representativos del concepto de historia científica de aquellos días, y su versión compendiada de la Introducción a los estudios históricos de Langlois y Seignobos, con aplicaciones al caso colombiano, que dio lugar a su Tratado de metodología y crítica bistórica y elementos de cronología colombiana de 1907. De su trabajo de archivo se desprendió una guía, Archivos Nacionales: indice analítico, metódico y descriptivo, de 1913, muy útil para los investigadores.

${ }^{12}$ Una muestra representativa de sus trabajos en el campo de las ciencias sociales se encuentra en Mendoza Pérez. Evolución de la sociedad colombiana (1994). 
disolución de los resguardos, la adjudicación de tierras baldías, la expropiación y la desamortización de bienes de manos muertas. Cada uno de estos estadios mostró la creciente afirmación del propietario individual y la correlativa decadencia de la propiedad comunal y de las normas que protegían los extensos dominios en manos de la Iglesia o del Estado e impedían la libre circulación de la tierra. Muchos de estos desarrollos se dieron en medio de revoluciones, alzamientos y disputas locales. Mendoza les recuerda a sus lectores que el progreso carece de escrúpulos y avanza destruyendo: "la historia prueba que todas las instituciones humanas han principiado por la violencia" (Mendoza, 1994, p. 173).

Con esta investigación Mendoza daba vida a su programa histórico-sociológico. Describía hechos, los ordenaba en una secuencia de largo alcance y los elevaba a generalizaciones que le ofrecían la posibilidad de enunciar una ley. Sus datos, tomados de la legislación, no se reducían a describir las actuaciones de los gobernantes o de las grandes personalidades; el centro era el pueblo, "la masa trabajadora de la nación":

E1 haber mirado insistentemente el lado político de nuestra historia, con exclusión casi completa de su faz social, nos ha mermado en forma notable el caudal de nuestros conocimientos, en términos que hoy generalmente se ignora cuál era la condición del pueblo en la época colonial, y cómo los cambios silenciosos de que hablaba lord Macaulay han venido trayéndonos por aluvión la mínima parte que del acervo común de la humana felicidad nos ha tocado. (ibíd., p. 86) ${ }^{13}$

E1 análisis de Mendoza era, por lo demás, muy sensible a las complejidades del análisis causal, que lo remitían al mutuo intercambio entre el orden jurídico y el orden económico. En sus páginas, el derecho se ajustaba a las demandas del progreso material y en medio de este proceso de larga duración se convertía en la vanguardia de las transformaciones sociales y materiales. Y lo más significativo era que a través de la elección de un segmento de la realidad -la propiedad-arrojaba luz sobre el curso general de la sociedad colombiana.

${ }^{13}$ La idea de Macaulay fue muy cara a los adalides de la historia científica fin de siècle. Provenía de su ensayo juvenil, History, traducido con excesiva liberalidad por el periodista Mariano Juderías Bender en 1885. Allí se planteaba que el historiador debía poner especial atención a los cambios graduales en los usos y costumbres, esto es, en las "revoluciones que generalmente se verifican sin ruido, sin tumulto, ni sangre, cuyos triunfos no se alcanzan nunca por la fuerza de las armas sino que van por su camino reposada y tranquilamente, ganando terreno en la escuela, en la iglesia, en el establecimiento comercial y en el hogar doméstico" (Macaulay, 1885, p. 373). 
Este proceso de individualización vinculado con la propiedad también fue estudiado por su camarada, el economista de vocación histórica, José Camacho Carrizosa, en Hombres y partidos, un boceto sociológico de la historia de Colombia ${ }^{14}$. Allí criticó la herencia de los historiadores del Renacimiento, muy dados a considerar la historia como una exposición de los resultados alcanzados por el hombre en el libre ejercicio de su voluntad. Contra esta postura, y sin desconocer la influencia de ciertas personalidades, subrayó "las leyes inmutables que gobiernan la conducta de los hombres". Esto lo llevó a afirmar que nuestra historia estaba por hacerse, labor que solo podía llevarse a cabo una vez se organizaran los archivos y se asimilaran los nuevos enfoques que daban cuenta de la marcha general del organismo social. Contra lo que pensaban los legisladores y sus adláteres, constitución no es el conjunto de ordenanzas enunciadas en una Carta sino los componentes básicos de la sociedad. Quien confunde esta última con su expresión jurídica se engaña y termina labrando en el mar. Los preceptos constitucionales se promulgan con facilidad, pero las sociedades tienen una organización y una tradición diferentes a los deseos y opiniones de los juristas de turno. "Las sociedades existen y tienen su manera de ser propia [y a] esto es lo que llamamos constitución" (1937, p. 93).

Este afán renovador fue seguido por algunos miembros de la Academia Colombiana de Historia, a la que pertenecía el propio Mendoza Pérez. Sus colegas, el antioqueño Jesús María Henao y el bogotano Gerardo Arrubla, autores de la festejada Historia de Colombia de 1911, suscribieron la nueva corriente historiográfica. "Escribimos -apuntaron con arrojo- procurando seguir las ideas expuestas y los métodos evolutivos modernos" a fin de ofrecer una apreciación más acabada de "los cambios silenciosos que se experimentan al través del tiempo", renunciando así a la antigua costumbre de historiar tan solo los sucesos políticos y militares. Querían resucitar el pasado en sus diversas fases mostrando lo que los hombres habían pensado y sentido sin dejar de lado las costumbres y las expresiones culturales ${ }^{15}$.

${ }^{14}$ Una síntesis de este agudo ensayo, publicado por entregas en el Repertorio Colombiano entre 1896 y 1897, fue recogida por la Biblioteca Samper Ortega en el volumen Artículos varios (1936), que comparte con su hermano, el periodista Guillermo Camacho. José Camacho murió tempranamente, a los cuarenta años, y no logró dar cima a su proyecto historiográfico orientado por la sociología.

15 Detrás de esto estaban las palabras de Macaulay grabadas en las primeras páginas de la Historia de Inglaterra. Allí anotó que su libro no se limitaba a registrar las batallas, el surgimiento y caída de los ministerios, las 
Y para acentuar su adhesión hicieron suyas las palabras de Ranke difundidas por la literatura secundaria: "deben contarse los hechos como han sucedido, no como pudieron y debieron ser". Confesaron, además, su fe positivista: fidelidad a los datos e imparcialidad en la valoración de los hechos. A lo largo del libro sustentaron las causas generadoras de los acontecimientos con testimonios, notas aclaratorias, registro de documentos y evaluación del trabajo de los investigadores que los habían precedido, pues se "considera deficiente la historia que no lleva citas fundamentales" (Henao y Arrubla, 1911, pp. 5 y 6). Su relato lo animaba un idioma pausado, natural y sencillo que recuerda el de La historia de la revolución de José Manuel Restrepo, donde la voluntad de los hombres parecía dejar su huella en los acontecimientos. El jurado calificador que recomendó el libro como texto de enseñanza apuntó:

[Los autores muestran] en su relato de los hechos y en sus juicios un criterio imparcial y el sincero propósito de ser fieles a la verdad; y en tal virtud se echa de ver que no mezclan a la narración apreciaciones que tienden a hacer prevalecer determinadas ideas o doctrinas, ni dar a los hechos distinta significación y distinto alcance del que realmente les corresponde. Esta condición de estricta imparcialidad hace la obra recomendable como texto de enseñanza. (citado en ibíd., pp. 9-10)

intrigas palaciegas o los debates parlamentarios. Su objetivo era más dilatado: relatar la historia del pueblo inglés. Para dar cuenta de este anhelo examinó sus formas de gobierno, el estado de las artes, el surgimiento de las sectas religiosas, las costumbres de las sucesivas generaciones y las transformaciones que habían tenido lugar en el gusto literario, los trajes, el mobiliario, las comidas y las diversiones públicas. Y concluyó: "acepto gustoso la censura que acaso se me haga de haber rebajado la dignidad de la historia" refiriendo tales minucias. Todo esto y más dio vida al famoso tercer capítulo de la Historia de Inglaterra dedicado a estudiar las condiciones sociales, demográficas, económicas y culturales de la Inglaterra de 1685, el año del ascenso de Jacobo II al trono (ver Macaulay, 1882, I, p. 5 y 1883, II, cap. 3). Respecto de la población, Macaulay consideraba que era la materia prima de toda investigación histórica. La historia es a fin de cuentas el registro de varias generaciones de hombres y mujeres asentados en un territorio. La nueva historia puso especial atención a esta demanda al concentrar una parte significativa de sus esfuerzos en establecer la estadística y distribución de los habitantes de la era precolombina, del periodo colonial y del sigo XIX.

La Historia de Macaulay fue muy apreciada durante el siglo XIX. Taine, que no se ahorró críticas, especialmente relacionadas con las licencias de su retórica, la calificó de "uno de los libros más hermosos del siglo" por la fuerza de su prosa, la amplitud de sus apreciaciones y el vigor del razonamiento. Allí Macaulay es "economista, literato, publicista, artista, historiador, biógrafo y hasta filósofo” (Taine, 1945, pp. 806 y 815). 
E1 libro portaba, además, un claro mensaje de formación política y moral; de instrucción cívica, como se decía en la época. Después de exponer los hechos como ocurrieron, o como se creía y se esperaba que hubieran acaecido, los autores subrayaron los ejemplos dignos de imitarse. A su juicio, la historia era una verdadera escuela de patriotismo, un conocimiento que promovía la admiración por el terruño, desde su nacimiento hasta nuestros días, manteniendo así generación tras generación los rasgos más queridos del carácter nacional ${ }^{16}$.

Algo semejante había planteado Eduardo Posada tres años antes en la sesión inaugural de la Academia Colombiana de Historia. Allí exaltó la naturaleza positiva de la historia, su vocación empírica, y como objetivo prioritario de la institución subrayó la organización de los archivos diseminados en manos privadas o en los olvidados anaqueles de las oficinas del Estado. "Tal [será] nuestra principal labor. No pretendemos por ahora -proclamó- escribir la historia de Colombia, sino arreglar esos materiales dispersos por ahí en todo el país, a fin de tenerlos listos para el sabio que venga a utilizarlos”. La historia es una ciencia y toda ciencia trabaja con datos. Y de este esfuerzo de veracidad y precisión deriva su utilidad. La historia no es

${ }^{16}$ En la versión compendiada para la enseñanza primaria, Henao y Arrubla (1911, pp. 187-188) acentuaron aún más el papel socializador de la historia: "La historia es la maestra de la vida, porque contiene grandes enseñanzas, múltiples ejemplos y modelos qué imitar. Conociendo el bien o el mal que han hecho los que nos precedieron en la existencia, ya como magistrados, ya como guerreros, ora como legisladores, en fin, todos aquellos que han ocupado en nuestro país posición influyente, podemos y debemos seguir solo el ejemplo de los buenos, teniendo como única mira el bien de la madre Colombia. A semejanza de nuestros mayores, seremos como leones para vencer o morir cuando la patria nos pida en su defensa la vida y todo. Es buen ciudadano el que conoce, ama y cumple sus deberes; honra la santidad de la religión y del hogar; respeta y obedece a la legítima autoridad; quiere más el bien público que el suyo propio, y aspira siempre al honor y al engrandecimiento de la patria".

Estos énfasis no eran nuevos en el campo de la historia. Eran familiares a toda sociedad en proceso de consolidación del Estado. Ya Droysen (1983, pp. 354-355) los había subrayado en su curso general de metodología histórica de 1857. Al interrogarse sobre la adhesión del historiador a su sociedad, a Prusia en su caso particular, rechazó la "objetividad de eunuco" que niega todo compromiso del historiador con su país. Para él la historia debía ejercer una función educativa para el Estado. "Mi obra es unilateral en todo sentido [...] Al considerar el pasado desde el punto de vista del pensamiento de mi pueblo y de mi Estado, de mi religión, me sitúo por encima de mi propio yo". Droysen consideraba que esta fidelidad era aún más necesaria, más grande y más fecunda, "cuanto menos formada y cuanto más lánguida sea todavía la conciencia estatal y nacional” de una nación. 
solo entretención que llena el apetito de lectores ávidos de noticias del pasado, también es fuente de enseñanzas. Además de afinar el amor patrio, ilustra los problemas del presente. "La historia se repite [y] bueno es conocer lo que pasó en otras edades para conjeturar lo que puede suceder en la nuestra”. Si bien es cierto que no está en capacidad de prever las revoluciones como el astrónomo anuncia los eclipses, la historia puede "conocer los caminos que han conducido a las naciones a la ruina o al engrandecimiento". Al mostrar lo sucedido se convierte en la mejor consejera del gobernante y de los ministros con capacidad de decisión. Ya lo había dicho Bossuet: si el príncipe requiere prudencia para reinar con éxito, nada más útil que conozca $\mathrm{y}$ haga suyas las lecciones de los tiempos antiguos que le ofrecen los historiadores (Posada, 1908, pp. 70, 71 y 77-78). Su postura era una extensión más de las enseñanzas de Comte. En cuanto disciplina que trabaja con hechos, la historia tendría la capacidad de "ver para prever, de estudiar lo que [fue] a fin de concluir de ello lo que serä" (Comte, 1934, p. 34) ${ }^{17}$.

Posada no dejó un trabajo de mayor calibre, pero junto a sus colegas de la Academia alentó la organización y publicación de importantes documentos de la Colonia y del siglo XIX. Murió en enero de 1942, a los ochenta años, cuando las librerías del país vendían los primeros ejemplares de la novedosa Economía y cultura en la bistoria de Colombia del joven Luis E. Nieto Arteta. A pesar del variado material que ofrecían sus textos, sus productos seguían la senda de la historia tradicional descrita por Tocqueville. Sus biografías eran muy dadas a la exaltación y a la descripción de acontecimientos como resultado de la entrega de unos pocos hombres de especial clarividencia. Abordó

17 Franjavier fue uno de los más sensibles a la exhortación comtiana. En uno de sus escritos advirtió que el hombre de Estado tenía sin duda mucho que aprender del pasado, pero siempre y cuando lo viese en movimiento, en sus relaciones de mutua dependencia. Las contiendas antiguas y sus eventuales resoluciones fueron tan complejas y enmarañadas como las del presente. Todo depende de la clarividencia y discernimiento del hombre de acción para evaluarlas. Esto lo llevó a escribir que "la política puede prever en tanto que no ignore su correlación con el orden económico, social, religioso, porque es el conocimiento del conjunto de tales fenómenos la luz que alumbra el próximo desarrollo de las instituciones en busca de un nivel que esté de acuerdo con las exigencias del medio y del tiempo en que vivimos" (Vergara y Velasco, 1906, p. viii). E1 asunto es complejo y continúa siendo objeto de atención por parte de los historiadores experimentados. "Admitir -escribió el veterano John H. Elliott (2012, p. 238)- que el presente está lleno de sorpresas exige un reconocimiento similar de que el pasado lo fue igualmente a ojos de quienes lo vivieron". 
un tema muy querido por la Nueva Historia, la esclavitud, pero su tratamiento no superó la glosa de la legislación sobre la trata y la libertad de los esclavos.

Todavía no se imponía la historia moderna, a pesar de que formalmente se conocían sus objetivos, sus procedimientos y sus cualidades. Faltaban las bibliotecas, la organización de los archivos, los centros de investigación, la preparación especializada y la existencia de una institución, una universidad, que combinara los afanes de la docencia con los desvelos de la investigación. Ante la precariedad de los fundamentos materiales del oficio no era todavía posible vivir de la historia para hacer historia. De tiempo en tiempo surgía una personalidad de talento que se comprometía con la redacción de un libro penetrante o la publicación de un ensayo brillante, pero a poco su voluntad perdía el aliento y se desvanecía ante las exigencias más apremiantes de la hora. El mismo Posada lo había dicho en su discurso inaugural:

Para escribir la historia se requieren hábitos de laboriosidad, de método y de orden; pasión por la verdad y la claridad; instrucción sólida, trabajo infatigable e inteligencia para abarcar un conjunto, formar un plan, distribuir los detalles y colocar con sobriedad los comentarios. (Posada, 1908, p. 78)

\section{VI}

El método de avanzar retrocediendo de los anteriores apartados nos muestra que los reclamos de la Nueva Historia no eran tan nuevos ni tan recientes y únicos como pensaban sus promotores. Su clamor contaba con un pasado pleno de enseñanzas. Sin ánimo adumbracionista -es decir, ensombrecer y restar importancia a una innovación mediante la exaltación de sus predecesores amparándose en el fallo del Eclesiastés (I,9), "nada nuevo hay bajo el sol"-, el caso colombiano muestra que el surgimiento de la historiografía moderna pasó al menos por tres largos períodos de afirmación y lucha -la de los años cincuenta, cuarenta y del novecientos- que prepararon la llegada de la Nueva Historia.

Pero cuando esta surgió sí hubo novedades bajo el cielo. Era más que una nueva vieja historia. La Nueva Historia superó las limitaciones de los anteriores esfuerzos por afirmar la historia como ciencia social estricta. Era sensible a los datos y a la teoría que daba cuenta de ellos. Antes hubo intentos individuales de unir la información de archivo con los desarrollos de las ciencias sociales -derecho, economía y sociología; demografía, antropología y geografía-, pero fueron experiencias frágiles y esporádicas. La generación fin de siècle, la del nove- 
cientos, cubrió un aspecto de la demanda del positivismo: la reunión de información. Con pocas excepciones, sus trabajos quedaron huérfanos de análisis, lo que solo podía hacerse retomando las enseñanzas de las ciencias sociales, disciplinas que ofrecían conceptos, enfoques y maneras de ver lo general en lo particular. "La historia no puede ser una ciencia más que si se eleva por encima de lo individual”, apuntó Durkheim en su controversia con los historiadores (1988, p. 290). Les faltó lo que Claude Bernard llamaba razonamiento, la operación de someter metódicamente las ideas a la experiencia de los hechos (1883, pp. 279-355). Se quedaron en los materiales y apenas avizoraron el hallazgo científico, la conceptualización del dato brusco que ofrece la observación. No parecían ser conscientes de que la investigación es solo una inquisición teóricamente orientada de la información acumulada. Ya lo había dicho Comte en su difundido Discurso sobre el espíritu positivo: profusión de hechos sin control conceptual es vana erudición, pues los hechos, "por numerosos y exactos que puedan ser, nunca procuran otra cosa que materiales" $(1934$, p. 33) 18 .

E1 impulso inicial lo dieron los discípulos de Jaramillo Uribe, que según su propia enumeración (1994, p. 306 y 2007, pp. 180186) incluía los nombres de Germán Colmenares, Jorge O. Melo, Margarita González, Jorge Palacios, Hermes Tovar, Isabel Sánchez, Víctor Álvarez, Germán Rubiano y Carmen Ortega. A ellos se unieron economistas, sociólogos y antropólogos, y un buen número de jóvenes investigadores provenientes del extranjero interesados en los problemas políticos, económicos y sociales de un país marginal del Tercer Mundo occidental, como lo fue Estados Unidos durante los lejanos años de la modernidad temprana. Ellos contaban con la obra de analistas solitarios que habían despejado el camino con anterioridad, como la del influyente geógrafo James J. Parsons sobre la colonización antioqueña, la del historiador del derecho indiano José María Ots Capdequí sobre las instituciones españolas en América, la de los etnohistoriadores Juan Friede y Reichel Dolmatoff sobre la conquista y las culturas precolombinas y la de la antropóloga Virginia Gutiérrez sobre el "trasfondo histórico" de la familia (1963). A su lado se hallaban las contribuciones de un joven formado en Estados Unidos, Orlando Fals Borda, que a los 32 años era autor de dos acreditados libros -Campesinos de los Andes (1955) y El hombre y

18 Estas reflexiones de teoría y método encontraron por aquellos días, en 1904, su síntesis más acabada en las palabras del físico y matemático Henri Poincaré: "Todo lo que el sabio crea en un hecho es el lenguaje en que lo enuncia” (1947, p. 148). 
la tierra en Boyacá (1957) - que exploraban la tenencia de la tierra y las modalidades del trabajo en la Colonia y en el siglo XIX. Una vez más, como lo revela la historia de la ciencia, toda cosa de importancia había sido dicha y hecha por personas que no llegaron a descubrirla (Whitehead, 1961, p. 167).

No hay que olvidar, por lo demás, que lo que era nuevo en el país era viejo y bien conocido en Alemania, Inglaterra, Francia, Estados Unidos y en los centros académicos más desarrollados de América Latina. La Nueva Historia consistió en la asimilación creativa de este legado, bien sea por la formación de sus miembros en los centros académicos del Primer Mundo o a través de un riguroso autodidactismo de discernimiento y síntesis, como fue el caso de Jaramillo Uribe, aunque no hay que descartar su experiencia alemana en Hamburgo durante los años cincuenta, su estancia en Francia a finales del decenio de los cuarenta y su aprendizaje en la Escuela Normal Superior con profesores europeos de calidad como Gerhard Masur -formado en Berlín bajo la égida de Friedrich Meinecke- o Rudolf Hommes, su profesor de historia antigua con buena formación en sociología. A estos ascendientes se sumaban las enseñanzas del medievalista Juan Francisco Cirre, alumno de Pirenne en Gante, y del geógrafo catalán Pablo Vila, difusor del mensaje de Vidal de la Blache en Colombia.

\section{VII}

Jaramillo se jubiló en la Universidad Nacional en 1970 y a continuación pasó a la Universidad de los Andes para proteger sus ingresos. Allí trabajó hasta su muerte casi centenaria. En los Andes tuvo numerosos estudiantes mas no discípulos. Su huella formativa y sus primicias intelectuales pertenecen al período de la Universidad Nacional, escenario donde fundó el Departamento de Historia y el Anuario Colombiano de Historia Social y de la Cultura, y donde publicó sus trabajos más representativos. Lo que hizo después fue un desarrollo y depuración de lo ya hecho. En un principio quiso reunir material para un libro sobre el siglo XVIII, la época de los virreyes, pero pronto abandonó el proyecto tornando su labor historiográfica por las sendas del ensayo, género en el cual fue un maestro ejemplar. Con Langlois y Signobos pensaba que el historiador no tenía derecho a escribir mal. Consideraba que "lo que se concibe bien se expresa con claridad" (Boileau, 1977, p. 122) y que se escribe bien cuando se piensa bien. Con estos aires tomados del Discurso sobre el estilo de Buffon (2014, pp. 333 y 335), que a veces atribuía a Pascal, sospechaba que "las obras bien 
escritas serán las únicas que pasarán a la posteridad”. En los textos de esta segunda etapa su prosa avanza jubilosa en medio de una frase clara y controlada plena de carga analítica que captura sin opresión los temas de estudio.

Los decenios de 1970 y 1980 fueron los años de los alumnos de Jaramillo y de los estudiosos de otras disciplinas que se unieron al proyecto de la Nueva Historia. Los economistas Miguel Urrutia, Salomón Kalmanovitz, Jesús Antonio Bejarano y José Antonio Ocampo difundieron por aquellos días sus libros más atendidos de historia económica. Lo mismo hicieron abogados de formación volcados sobre la historia social y política como Álvaro Tirado Mejía, Marco Palacios y Eduardo Posada Carbó con obras que cubrían los siglos XIX y XX. A ellos se sumó una camada de investigadores provenientes de Europa y Norteamérica, entre los cuales se encontraban, para solo mencionar a los más persistentes y de mayor influjo, David Bushnell, Frank Safford, Charles Bergquist, Malcolm Deas, James Henderson, Stephen J. Randall, William P. McGreevey, Jane Rausch y Aline Helg ${ }^{19}$.

Los alumnos de Jaramillo, convertidos ahora en sus colegas, tuvieron una predilección por la Colonia y la primera mitad del siglo XIX, los años de la manumisión. La lejanía parecía conferirles objetividad y control valorativo ante las tensiones de su propia sociedad. Germán Colmenares se destacó por una serie de monografías desprendidas de acuciosos trabajos de archivo donde examinó la esclavitud, la tenencia de la tierra, la población y el trabajo indígena y esclavo. Le siguió de cerca Margarita González con estudios sobre el resguardo, el estanco y la liberación de los esclavos, esfuerzo que fue continuado por Jorge Palacios Preciado con la exploración de la trata de negros en Cartagena y por Hermes Tovar con múltiples publicaciones sobre la vida colonial, el mundo precolombino y las tensiones políticas durante los siglos XIX y el XX. Jorge Orlando Melo no escapó al momento colonial. Se inició con una ambiciosa historia de Colombia que partía del siglo XVI, Descubrimiento y Conquista, relato que aspiraba a llegar hasta el siglo XX, pero solo publicó una entrega, un novedoso fresco del establecimiento de la dominación española en el territorio de lo que hoy es Colombia. Después se embarcó en una larga y sostenida labor de difusión de materiales históricos para el gran público en el formato del ensayo y del libro de texto. Víctor Álvarez se adentró por las sendas de la historia empresarial, Isabel Sánchez se inclinó por la

19 Para una lista más completa de los eruditos extranjeros sobre Colombia, ver Los colombianistas (2015) de V. Peralta y M. LaRosa. 
docencia y Germán Rubiano tomó el rumbo de la historia del arte con especial énfasis en el siglo XX. Carmen Ortega no superó la historia tradicional, pero dejó un útil Diccionario de artistas en Colombia (1979) que el tiempo ha ido apolillando. Estos investigadores, y sus colegas de disciplinas aledañas, tejieron un esprit de corps al asumir la redacción de los variados capítulos de los tres robustos tomos del Manual de historia de Colombia (1978-1980) bajo la coordinación de Jaramillo Uribe, obra que selló la renovación temática del pasado a la luz de las contribuciones más recientes de las ciencias sociales ${ }^{20}$.

El éxito de la Nueva Historia no residió solo en su fuerza analítica sino en su carácter colectivo. Sus miembros fundaron escuelas de historia en varias capitales del país y lo que inicialmente era una empresa de historiadores arrastró consigo a las demás ciencias sociales hasta convertirse en un movimiento de eruditos con afinidades teóricas y empíricas. Esto hizo que los mejores representantes de las ciencias sociales nacionales se comprometieran en algún momento de su vida con un trabajo de historia, y que vieran en ella una disciplina de afirmación y síntesis de lo social. Ni siquiera el retraído demógrafo Álvaro López Toro fue extraño a esta aventura. Dos años antes de su suicidio publicó Migración y cambio social en Antioquia en el siglo $X I X(1970)$, un agudo ensayo sobre la minería, la agricultura y el comercio en una región apartada del país que mostraba una dinámica económica particular.

Los miembros de la Nueva Historia fueron, además, excelentes divulgadores de su proyecto intelectual. Escribieron cartillas para la enseñanza y coordinaron compendios y textos colectivos para el gran público. Antes del Manual apareció la Historia del arte colombiano (1975), dirigida por el historiador de las artes visuales Eugenio Barney-Cabrera, seguida por Colombia hoy (1978), coordinado por Mario Arrubla, y por la Historia de Colombia (1987a) bajo la dirección científica de Gonzalo Hernández de Alba. A estos ejemplos se unieron la Historia económica de Colombia (1987b), a cargo de José Antonio Ocampo, la Nueva historia de Colombia (1989), dirigida por Álvaro Tirado Mejía, y la Gran enciclopedia de Colombia (1991-1993), editada por Camilo Calderón Schrader. A continuación llegaron las historias

${ }^{20}$ Este grupo ya había dado el paso inicial con el libro colectivo La nueva historia de Colombia, compilado por el poeta Darío Jaramillo Agudelo en 1976. El volumen dio carta de ciudadanía a los historiadores caracterizados -según el compilador- por una historia social, económica y regional basada en fuentes primarias, énfasis que contrastaba con la historia tradicional, cuyo fin es crear un sentimiento de patria en la juventud exaltando las virtudes de los padres fundadores (Varios, 1976, pp. 12 y 13). 
regionales, La historia de Antioquia (1988) y la Historia de Medellín (1996), ambas coordinadas por Jorge O. Melo. Pero la gran novedad la constituyeron los fascículos ilustrados de la Revista Credencial Historia, auspiciada por el Banco de Occidente, que en su periodo inicial -1990-2004-, bajo la coordinación del incansable Camilo Calderón, el mayor animador gráfico de los estudios históricos del país, alcanzó a sacar 171 entregas que rebasaban los 70.000 ejemplares mensuales (Cataño, 2000, p. 104) ${ }^{21}$.

Las contribuciones de estos textos generales, de múltiples plumas, son sin duda disparejas y de tonalidad diversa. Sus coordinadores debieron echar mano de autores con distinta formación y muchos temas apenas habían sido explorados, lo que hacía que las síntesis partieran de informaciones endebles no siempre seguras y concluyentes. No obstante, cumplieron la función de of recer un relato más fresco y comprensivo a un público deseoso de conocer el desenvolvimiento de la nación en los campos de la economía, la sociedad y la cultura. Los tomos se agotaban y las segundas y terceras ediciones salían a la calle para nutrir las apetencias de los lectores.

\section{VIII}

Para 1990 la Nueva Historia había dado sus mejores frutos y su proyecto académico estaba suficientemente consolidado. Era el marco de referencia dominante en la universidad y en los centros de investigación. La labor de los académicos, la historia "tradicional" empotrada en las academias regionales y en la Academia Colombiana de Historia, continuaba, pero en medio de un trabajo marginal de diletantes y aficionados que apenas tenía seguidores más allá de sus gerontocráticos recintos volcados sobre las glorias del pasado.

Con la temprana desaparición de Germán Colmenares en 1990, su líder más conspicuo, se dan por concluidas las tareas de la primera generación de la Nueva Historia. Para ese momento los logros del movimiento eran claros. Se habían afirmado la historia económica, el estudio de los conflictos sociales y el examen de la diferenciación social. Junto a ello se habían esclarecido las formas de trabajo, la lucha por la tierra y la fuerza de ciertas instituciones para el manejo de la población que caracterizó la dominación española en América. Era un énfasis en los fenómenos de estructura social, basado en fuentes

${ }^{21}$ Después la retomó el historiador Juan Camilo Rodríguez, quien coordinó 114 números entre 2007 y 2016, con entregas temáticas ilustradas tan diversas como la historia del arte, de las ciudades, la política, la industria y la navegación por el río Magdalena. 
primarias, que reaccionaba contra la narrativa suelta y el biografismo de exaltación que atendía más al goce estético que al contenido de lo que se deseaba exponer.

En la afirmación de estos acentos la Nueva Historia se aprovechó de la presencia del marxismo en la vida universitaria de los años sesenta y setenta. Buena parte de sus cultivadores eran de izquierda, y el mismo Jaramillo había estado en su juventud muy cerca de los grupos radicales de los años cuarenta y conocía el legado de Marx. Además, el uso que Nieto Arteta y Hernández Rodríguez habían dado a ciertas hipótesis del materialismo histórico, como la centralidad de los fundamentos materiales, había aireado el estudio del pasado. En esto ayudó Liévano Aguirre con la afirmación del conflicto de clases como elemento esencial de la experiencia nacional. Era un marxismo abierto, sin cortapisas ideológicas y muy sensible a otras tradiciones historiográficas, como las provenientes de la escuela francesa de los Annales o de la sociología alemana de Max Weber y Werner Sombart, que en su momento también habían sentido la influencia del marxismo. La visión era muy parecida a la de un historiador inglés de ascendencia noruega interesado en los movimientos sociales, George Rudé, muy atendido por los miembros de la Nueva Historia:

Aprendí que las vidas y las acciones de la gente común constituyen el contenido mismo de la historia, y que aun cuando los factores materiales tienen precedencia sobre los institucionales o ideológicos, las propias ideas se convierten en una fuerza material al entrar en la conciencia activa de los hombres. (Rudé, 1975, p. 207)

Pero después de la muerte de Germán Colmenares florece una segunda generación con problemas particulares. Camadas de estudiantes se gradúan en los departamentos de historia de la capital y de las ciudades de provincia, y las becas, las maestrías y los doctorados nacionales y extranjeros se multiplican. Surgen nuevos temas y se vigorizan los de antaño, descuidados por la primera generación que tendió a subrayar los fundamentos materiales de la acción social, ahogando los idearios y los aspectos culturales. Surge una presión sobre los archivos, y los funcionarios de las bibliotecas y de los centros de documentación se ven agobiados ante un hervidero de jóvenes que adelantan sus prácticas de investigación y sus tesis de licenciatura, maestría y doctorado. Ahora la historia tiene rasgos profesionales con signos de masificación, y sus miembros se ven cercados por dificultades ocupacionales ignoradas por la generación precedente ${ }^{22}$.

${ }^{22}$ La historia - como la economía, la sociología, la geografía y la antropología- es una disciplina "sencilla". El estudiante normal que se matricula en 
La primera reacción de esta segunda generación de la Nueva Historia provino de la historia política unida a la cultura y a los problemas étnicos. La llamada Nueva Historia -apuntó un investigador de los conflictos raciales- "estuvo demasiado preocupada por entender los grandes procesos sociales y económicos [mostrando] poco interés por los asuntos de la política y la cultura" (Múnera, 1998, p. 15). Se tendió a situar en un segundo plano el papel de las "mentalidades"-ideas, actitudes y valores; religión, cultura y modos de vida- ante el peso de las fuerzas sociales y económicas que parecían cercar la existencia de los individuos y de los grupos. La nueva generación reaccionó contra los enfoques más estrechos de la tradición marxista y de la escuela de los Annales que subrayaban las fuerzas impersonales de la historia: las condiciones materiales, el entorno físico, la educación, las clases sociales, el aparato de gobierno, etc. Se hablaba de estructura, y en medio de ella desaparecían los hombres y mujeres que la sufrían y la habían erigido. Estas perspectivas analíticas de exterioridad subrayaban el contexto y descuidaban las condiciones particulares del hombre común. Se descuidaba la agencia humana, la acción de individuos y grupos. Como recordó un experimentado analista, "el historiador debe estar siempre alerta al papel del azar -el retraso en la llegada de una carta, la mala interpretación de unas instrucciones, la muerte

un departamento de historia avanza sin mayores dificultades en el cumplimiento de sus deberes y con sorpresa observa que los semestres se suceden uno tras otro hasta alcanzar el anhelado título. Se sabe, sin embargo, que un historiador competente, para no decir sobresaliente, es una rareza. ¡E1 mundo de las ciencias sociales es un terreno fácil en el que pocos descuellan! En estos entornos la aglomeración apenas salva el decoro. La imaginación, dedicación y entrega, la vocación, juegan aquí un papel prominente.

Atendiendo las reflexiones de Keynes (1992, p. 185) para el caso de los economistas, debemos decir que el estudio de la historia exige una combinación de dotes que pocas veces se encuentran en una sola persona. E1 historiador debe estar familiarizado con el desarrollo de su disciplina, con las obras más representativas del oficio (los "clásicos") y con los problemas de teoría y método que tejen, o han tejido, sus maneras de hacer. De alguna manera debe ser un jurista, un filósofo, un artista, un psicólogo, un demógrafo, un sociólogo, un antropólogo y un geógrafo. Ninguna de estas disciplinas y formas de percibir lo social deberían quedar por fuera de su interés. El objeto de estudio, la naturaleza humana en los más diversos contextos institucionales del pasado, lo exige. Estos saberes son los que, por lo demás, le facilitan la observación de lo particular en términos de lo general y lo disponen a palpar lo abstracto y lo concreto como manifestaciones de un mismo impulso del pensamiento. Y, claro, historiador que ignore los secretos del idioma se verá en dificultades para comprender el clima de sus fuentes y redactar de manera persuasiva sus hallazgos y la fuerza y cadencia de su argumentación. 
inesperada de una figura influyente- en cualquier intento de descubrir por qué ocurrieron las cosas de la manera en que lo hicieron" (Elliott, 2003, p. 36).

Contra el énfasis de clase surgió la noción de raza aportada por los antropólogos para explicar la diferenciación social y las fuentes de los conflictos en regiones enteras del territorio, especialmente en el Caribe colombiano. A este tema se unió el de la construcción de la nación y del Estado, y junto a ellos el de la política, tan descuidada por la generación anterior. El mismo Jaramillo Uribe se dio cuenta de estos vacíos y al final de su vida recordó la necesidad de volver sobre la historia política, que acentúa la configuración del Estado, las luchas por el poder y la búsqueda de la paz, la seguridad y la justicia. Siguiendo las enseñanzas de Hegel, su autor preferido en asuntos de teoría de la historia, no dudó en afirmar que es en la política donde al final se definen los problemas esenciales del género humano (Cataño, 2005, pp. 74-76) 23 .

Como eco de la renovación del estudio de las revoluciones hispánicas emprendido por el hispano-galo François-Xavier Guerra, la crisis del régimen colonial, 1810, la Patria Boba y la Pacificación han vuelto a ser objeto de investigación con enfoques diferentes a los de los académicos. Las luchas sindicales y los movimientos obreros y campesinos, un terreno de los grupos de izquierda, han resurgido con nuevas metodologías y un acervo documental más rico y sistemático que el que se usaba para nutrir las luchas ideológicas. Ya no se ven las clases en términos meramente socio-económicos sino como grupos portadores de una cultura-creencias y aspiraciones particulares- que inspira y define el curso de sus combates. Algo similar ha sucedido con los estudios de género. Una tensión de la sociedad actual, la diferenciación social de la mujer, ha dado lugar a un fructífero campo de investigación. ¡Es un ejemplo más del presente que busca réplicas en el pasado! Grupos reducidos de economistas se vuelcan sobre la cliometría, la aplicación de métodos cuantitativos y de modelos conductuales de las ciencias sociales al estudio de la historia. En forma

${ }^{23}$ Este interés por la política también revirtió sobre algunos miembros de la primera generación de la nueva historia. Ya en los años ochenta Álvaro Tirado había publicado Aspectos políticos del primer gobierno de Alfonso López Pumarejo (1981) y en la década siguiente Marco Palacios difundió Entre la legitimidad y la violencia, una historia política de Colombia entre 1875 y 1994 (1995). Hay que reconocer que Palacios ha tenido siempre una inclinación por el estudio de los conflictos sociales y el papel del Estado en el desenvolvimiento del país. Su notable trabajo de 1979, El café en Colombia, tenía el subtítulo: "Una historia económica, social y política". 
callada han promovido una redefinición de la antigua contraposición historia científica-historia tradicional. Para ellos, la científica consiste en el control cuantitativo de las variables que se incluyen en la investigación, y la tradicional es la que subraya lo individual y recurre a la narrativa para exponer la dinámica de los hechos. Los cliometristas tienden a argumentar que si la historia es una ciencia, la mejor manera es hacer suya la senda de la cuantificación.

Pero quizá la reacción más fuerte ha sido el rescate de la historia de las ideas, y dentro de este subcampo el de la historia intelectual y de la cultura. Esto ha servido para introducir de nuevo en la agenda el género biográfico, tan descuidado por la Nueva Historia, temerosa de conferir demasiado juego a las personalidades. Algunas figuras intelectuales y políticas de los siglos XIX y XX han sido estudiadas con fuentes novedosas; sin embargo, la mayoría de sus autores todavía no se desprenden de la hagiografía, del entusiasmo por las cualidades de sus héroes hasta convertirlos en modelos de pensamiento y acción.

Más temas y una delimitación novedosa de los anteriores circulan por la nueva generación de historiadores. Muchos surgen de vacíos en el saber y otros, no pocos, son eco de novedades europeas y norteamericanas que se busca traer al país o que el medio demanda para cubrir exigencias del momento. Es el caso de la reconstrucción de la memoria a través de la historia oral practicada por sociólogos y antropólogos que se dieron a la tarea de reunir información difícil de obtener en los archivos oficiales. Es de esperar que el campo crezca con el proceso de justicia transicional que vive el país, ya que el éxito de los juzgados especiales y de las comisiones de la verdad depende del rigor y la veracidad con que se recojan las experiencias de las víctimas y los victimarios. Aquí la historia oral es útil para revivir la experiencia de campesinos, guerrilleros, cocaleros, paramilitares y soldados del Ejército Nacional. Es una versión del presente como historia, de sucesos de nuestros días que serán examinados como pasado de gran significado por las futuras generaciones (Sweezy, 1968, p. 9). La historia se desliga ahora de los tiempos remotos para convertirse en historia contemporánea, en el registro, interpretación y análisis de sucesos que circundan la vida misma del historiador. Es la época en que trabaja con una documentación viva dispuesta a controvertir sus explicaciones, hecho que no sucedía cuando se ocupaba de la documentación inerme de siglos anteriores (Erlij, 2018) ${ }^{24}$.

${ }^{24}$ La memoria está llena de peligros. Se sabe que es individual, afectiva y emotiva; un pasado-presente que no se desliga de la personalidad de quien la expresa. Es labor del historiador controlar sus desviaciones atendiendo a 
La recuperación de la memoria es un campo que los historiadores comparten con los demás científicos sociales, además de periodistas y escritores. En Europa ha sido provechosa para el estudio de los sobrevivientes del nazismo y del furor soviético, como lo ha hecho la Nobel de literatura Svetlana Alexiévich en varias obras sobre el estalinismo. En las Américas, el estudio de la esclavitud se vio favorecido con las historias de vida y las entrevistas en profundidad con antiguos esclavos. El ejemplo más recordado en nuestra América es la Biografía de un cimarrón, del escritor y antropólogo Miguel Barnet (1966), que recupera la vida de un esclavo de 108 años que trabajó en los ingenios azucareros cubanos de la segunda mitad del siglo XIX. En estas incursiones lo acaecido no es ya asunto exclusivo de los historiadores. Por sus predios hoy rondan las más diversas disciplinas, con técnicas de investigación, recolección y análisis de datos que enriquecen los archivos, la tradicional morada de los discípulos de Ranke. Con sus contribuciones "el pasado se ha convertido en un campo abierto en el que se sienten libres de errar a su antojo los representantes de todas las disciplinas humanísticas" (Elliott, 2012, p. 12).

En medio de estas primicias ha brotado un manifiesto deseo de derrumbar el estatus científico de la historia. Ahora es corriente escuchar la expresión "una mirada”, con la cual se quiere significar que toda aproximación a un tema de estudio es igualmente legítima. E1 asunto y los datos son los mismos, pero los atisbos y el vocabulario que les sirven de orientación son tan disímiles como los analistas que los examinan. Los hechos se desvanecen, se deshacen ante los ojos del investigador hasta hacer de la historia una disciplina de los varios testimonios o recurriendo a fuentes impresas para frenar el ímpetu subjetivo de los entrevistados o de los que se acercan a los medios de comunicación de masas para acentuar sus confesiones. Esto no descarta sin embargo su utilidad. Es un instrumento para ilustrar situaciones difíciles de conocer por otros medios; un atajo para escuchar las voces de grupos marginales carentes de recursos y de las habilidades del alfabetismo. Los jueces la usan a diario en las querellas judiciales.

Consciente de estas limitaciones, Droysen (1983, pp. 78-79) llamó la atención sobre las distorsiones de la memoria. En una de sus pláticas de Histórica le reveló a los estudiantes que solo basta observarnos a nosotros mismos para saber cuán difícil es mantener los recuerdos, y cómo se desplaza y se modifica la imagen de lo que se ha visto o se ha hecho y se ha ayudado a hacer. La casa o la ciudad en la que vivíamos cuando éramos niños parecen completamente distintas cuando las visitamos diez o veinte años después de haberlas abandonado. Al regresar las vemos más pequeñas y pedestres, a pesar de que siguen siendo las mismas. "No es el lugar -señaló Droysensino nosotros y con nosotros nuestra representación del lugar lo que se ha transformado". 
modos de ver y de sentir del observador, muy parecida a la forma como los viajeros del siglo XIX percibían y valoraban una misma institución o un mismo tipo racial siguiendo los idearios que traían de sus respectivos países. Es una manifestación de la historia posmoderna: el relato histórico está atravesado por múltiples mediaciones y un mismo acontecimiento o proceso puede ser visto desde distintas perspectivas. Es el laudo de Poincaré, sin cortapisas: "todo lo que el sabio crea en un hecho, es el lenguaje en que lo enuncia”. Aquí la noción de verdad se diluye y el saber se concibe como la suma de múltiples narrativas consideradas igualmente válidas. Pero ante estos ímpetus que no parecen tener freno hay que recordar que el hecho bruto no se puede olvidar; está allí, es el progenitor del hecho científico que lo enuncia y a él volverán los críticos para controlar la imaginación y ensueño del investigador. Detrás de esto está, por supuesto, la vieja discusión sobre cómo se recrea el ayer, asunto que ha acompañado la disciplina histórica desde su nacimiento, y al cual han respondido las más diversas corrientes filosóficas sin llegar a una solución satisfactoria para los historiadores y los críticos del conocimiento. Quizá lo más indicado sería concluir que el escrutinio del pasado está rodeado de múltiples interpretaciones y que no hay respuestas absolutas, sino un diálogo continuo en medio del respeto por los datos y la severidad intelectual en el tratamiento de la información (Iggers, 2012, p. 261).

Con todas las dificultades que pueda tener la historia en el país, y los altibajos de calidad debidos al gran aumento de establecimientos formativos, se observa que es una disciplina establecida que reúne las condiciones básicas de la ciencia y corre pareja con las demás disciplinas que examinan lo social. Ha tenido la capacidad de integrarlas en un marco comprensivo, haciendo que toda ciencia social que merezca ese nombre no pueda evadir el fondo histórico que anima su particular objeto de estudio. A pesar de los acentos subjetivos de la hora, todavía impera el control factual examinado a la luz de un marco de referencia que busca integrar lo general con lo particular, lo individual con lo colectivo. Para atender las más aceradas pretensiones de los cliometristas y animar a los historiadores "tradicionales" más sensibles a los datos y al control conceptual podemos decir de nuevo con Durkheim, autor de un notable estudio de naturaleza histórica, La evolución pedagógica en Francia:

cuando se hace de la historia una ciencia se le asigna como objeto no los pormenores de los acontecimientos particulares sino las instituciones, las costumbres, las creencias, en una palabra, las realidades colectivas, cuya 
constancia y regularidad se contrapone a la contingencia y a la extrema fluidez de los hechos individuales. (Durkheim, 1988, p. 288)

Aquí las realidades colectivas confieren orden y significado a los hechos individuales, que fácilmente se traducen en anécdota cuando carecen de un marco que fije su papel en el conjunto de la sociedad. Pero también y de manera significativa, los hechos agitan los esquemas que tienden a reificarse cuando los analistas olvidan las manifestaciones particulares. Es el papel de la microhistoria que, además de preguntarse qué hay de representativo en las experiencia de un individuo o en la vida de una pequeña comunidad, pone en cuestión las seductoras generalizaciones de la macrohistoria, muy dada a cultivar el trazo global de una sociedad - un reino, un Estado, una naciónoscureciendo las singularidades de sus elementos constitutivos.

\section{REFERENCIAS BIBLIOGRÁFICAS}

\section{LIBROS Y ENSAYOS}

Aguilera, M. (2008). Carta a Bernardo J. Caycedo, presidente de la Academia Colombiana de Historia, Bogotá, 25 de noviembre de 1962. En Rueda E., J. E. Juan Friede, 1901-1990: vida y obras de un caballero andante en el trópico (pp. 465-466). Bogotá: Instituto Colombiano de Antropología e Historia.

Altamira, R. (1895). La enseñanza de la historia [1891]. Madrid: Librería de Victoriano Suárez.

Barnet, M. (1966). Biografía de un cimarrón. La Habana: Instituto de Etnología y Folklore.

Berlin, I. (1983). El concepto de historia científica [1960]. En Conceptos $y$ categorias: ensayos filosóficos (pp. 179-236). México DF: Fondo de Cultura Económica.

Bernard, C. (1883). Tratado del raciocinio experimental [1865]. En Guzmán, C. C. (comp.) Curso de filosofía experimental (pp. 279-355). Bogotá: Imprenta de Medardo Rivas.

Bernheim, E. (1889). Lehrbuch der historischen Methode. Leipzig: Duncker \& Humblot.

Bernheim, E. (1937) Introducción al estudio de la historia [1905]. Barcelona: Labor.

Betancourt M., A. (2007). Historia y nación: tentativas de la escritura de la historia en Colombia. Medellín: La Carreta.

Bolieau, N. (1977) [Arte] Poética [1674]. En González P., A. (ed.). Poéticas: Aristóteles, Horacio, Boileau (pp. 11-151). Madrid: Editora Nacional.

Buffon, conde de. (2014). Discurso sobre el estilo [1753]. Revista de Economia Institucional, 16(31), 333-339.

Camacho C., J. (1896-1897). Hombres y partidos. Repertorio Colombiano, $14(4,5$ y 6$)$ y $15(2)$.

Camacho C., J. y Camacho C., G. (1936). Artículos varios. Bogotá: Minerva. 
Cataño, G. (2000). Crítica sociológica y otros ensayos. Bogotá: Universidad Externado de Colombia.

Cataño, G. (2005). Afirmaciones y negaciones: maestros del siglo XX. Bogotá: Universidad Externado de Colombia.

Cataño, G. (2013). La introducción del pensamiento moderno en Colombia. el caso de Luis E. Nieto Arteta. Bogotá: Universidad Externado de Colombia.

Comte, A. (1934). Discurso sobre el espiritu positivo [1844]. Madrid: Revista de Occidente.

Cuervo M., E. (1938). Introducción al estudio de la filosofía de la historia. Bogotá: ABC.

Droysen, J. G. (1983). Histórica: lecciones sobre la enciclopedia y metodología de la historia. Barcelona: Alfa.

Durkheim, É. (1988). La historia y las ciencias sociales [1903]. En Las reglas del método sociológico y otros escritos sobre filosofía de las ciencias sociales (pp. 288-291). Madrid: Alianza.

Durkheim, E. (1982). Historia de la educación y de las doctrinas pedagógicas. la evolución pedagógica en Francia [1938]. Madrid: La Piqueta.

Elliott, J. H. (2003). España en Europa: estudios de historia comparada. Valencia: Universitat de València.

Elliott, J. H. (2012). Haciendo historia. Madrid: Taurus.

Erlij, E. (2018). Entrevista a Pierre Nora: el historiador es un árbitro de las diferentes memorias. Letras Libres, 230, 22-27.

Fals B., O. (1961). Campesinos de los Andes [1955]. Bogotá: Universidad Nacional.

Fals B., O. (1957). El hombre y la tierra en Boyacá. Bogotá: Ediciones Colombianas.

Flint, R. (s. f.). Filosofía de la bistoria en Alemania [1878]. Madrid: La España Moderna.

Flint, R. (1894). History of the philosophy of history. Nueva York: Charles Scribner's Sons.

Friede, J. (1964a). La investigación histórica en Colombia, Boletín Cultural y Bibliográfico, 7(2), 220-224.

Friede, J. (1964b). La investigación histórica, Boletín Cultural y Bibliográfico, 7(9), 1582-1586.

Gómez H., R. (1964). Réplica a las observaciones críticas del académico Friede. Boletín Cultural y Bibliográfico, 7(6), 988-993.

Gutiérrez de P., V. (1963). La familia en Colombia: trasfondo histórico. Bogotá: Universidad Nacional.

Guzmán, C. C. (comp.). (1883). Curso de filosofía experimental. Bogotá: Imprenta de Medardo Rivas.

Henao, J. M. y Arrubla, G. (1911). Compendio de la bistoria de Colombia para la enseñanza en las escuelas primarias de la República. Bogotá: Imprenta Eléctrica.

Henao, J. M. y Arrubla, G. (1911-1912). Historia de Colombia para la enseñanza secundaria, 2 vols. Bogotá: Escuela Tipográfica Salesiana.

Hernández R., G. (1949). De los chibchas a la Colonia y a la República. Bogotá: Universidad Nacional de Colombia. 
Iggers, G. G. (2012). La historiografía del siglo XX. Santiago de Chile: Fondo de Cultura Económica.

Isaacs, J. (2005). María [1867]. Bogotá: Universidad Externado de Colombia.

Jaramillo U., J. (1964). El pensamiento colombiano en el siglo XIX. Bogotá: Temis.

Jaramillo U., J. (1994). De la sociología a la historia. G. Cataño (comp.). Bogotá: Uniandes.

Jaramillo U., J. (2007). Memorias intelectuales. Bogotá: Taurus.

Keynes, J. M. (1992). Ensayos biográficos [1933]. Barcelona: Crítica.

Lacombe, P. (1948). La historia considerada como ciencia [1894]. Buenos Aires: Espasa-Calpe.

Langlois, Ch. V. y Seignobos, Ch. (1913). Introducción a los estudios históricos [1898]. Madrid: Jorro.

Liévano A., I. (1944). Rafael Núñez. Bogotá: Cromos.

Liévano A., I. (1950). Bolivar. Bogotá: El Liberal.

Liévano A., I. (1961). Los grandes conflictos sociales y económicos de nuestra historia. Bogotá: Ediciones Nueva Prensa.

López T., Á. (1970). Migración y cambio social en Antioquia en el siglo $X I X$. Bogotá: Universidad de los Andes.

Macaulay, Lord. (1885). De la historia [1828]. En Vidas de politicos ingleses (pp. 333-379). Madrid: Luis Navarro Editor.

Macaulay, Lord. (1882-1884). Historia de la revolución de Inglaterra [1848], 4 tomos. Madrid: Librería de la viuda de Hernando.

Melo, J. O. (1979). Sobre historia y politica. Medellín: La Carreta.

Mendoza P., D. (1994). Evolución de la sociedad colombiana, ensayos escogidos. G. Cataño (comp.). Bogotá: Universidad Externado de Colombia.

Monod, G. (s. f.). La historia. Bogotá: Imprenta Moderna.

Múnera, A. (1998). El fracaso de la nación: región, clase y raza en el Caribe colombiano, 1717-1810. Bogotá: Banco de la República, E1 Áncora Editores.

Nieto A., L. E. (1941). Economía y cultura en la historia de Colombia. Bogotá: Ediciones Librería Siglo XX.

Nieto A., L. E. (1978). Ensayos históricos y sociológicos. Cataño, G. (comp.). Bogotá: Instituto Colombiano de Cultura.

Núñez, R. (1874). Ensayos de crítica social. Ruan: Imprimerie de E. Cagniard.

Núñez, R. (1945-1950) La reforma política, 7 vols. Bogotá: Biblioteca Popular de Cultura Colombiana.

Ortega R., C. (1979). Diccionario de artistas en Colombia. Bogotá: Plaza y Janés.

Ospina V., L. (1955). Industria y protección en Colombia: 1810-1930. Medellín: E.S.F.

Palacio, M. (1979). El café en Colombia (1850-1970): una historia económica, social y politica. Bogotá: Presencia.

Palacios, M. (1995). Entre la legitimidad y la violencia: Colombia, 18751994. Bogotá: Norma.

Pascal, B. (2012). Pensamientos, opúsculos, cartas. Madrid: Gredos. 
Peralta, V. y LaRosa, M. (2015). Los colombianistas. Bogotá: Academia Colombiana de Historia.

Poincaré, H. (1947). El valor de la ciencia [1904]. Buenos Aires: EspasaCalpe.

Posada, E. (1908). Discursos y conferencias. París: A. \& R. Roger y F. Chernoviz.

Posada, E. (1933). La esclavitud en Colombia. Bogotá: Imprenta Nacional.

Reclus, E. (1893). Colombia. Trad. y notas de F. J. Vergara y V. Bogotá: Papelería de Samper Matiz.

Rudé, G. (1975). E1 rostro cambiante de la multitud. En Curtis, L. P. (comp.). El taller del historiador (pp. 207-223). México DF: Fondo de Cultura Económica.

Rueda E., J. E. (2008). Juan Friede, 1901-1990: vida y obras de un caballero andante en el trópico. Bogotá: Instituto Colombiano de Antropología e Historia.

Saavedra F., D. (1988). Empresas politicas [1642]. Barcelona; Planeta.

Sanín C., B. (2006). Tiranía del medio ambiente [1904]. En Revista Contemporánea: 1904-1905 (pp. 292-299). Bogotá: Universidad Externado de Colombia.

Strachey, L. (1997). Retratos en miniatura [1931]. Madrid: Valdemar.

Suárez, M. F. (1958-1980). Obras, 3 vols. Bogotá: Instituto Caro y Cuervo.

Sweezy, P. M. (1968). El presente como historia. Madrid: Tecnos.

Taine, H. (1945). Historia de la literatura inglesa [1864]. Buenos Aires: Américalee.

Tirado M., Á. (1981). Aspectos politicos del primer gobierno de Alfonso López Pumarejo: 1934-1938. Bogotá: Procultura.

Tirado M., Á. (2014). Los años sesenta: una revolución en la cultura. Bogotá; Debate.

Tocqueville, A. de. (1989). La democracia en América II [1835-1840]. Nolla, E. (ed. y trad.). Madrid: Aguilar.

Tocqueville, A. de. (1837). De la democracia en la América del Norte [1835], 2 tomos. Sánchez de B., D. (trad.). París: Rosa.

Tocqueville, A. de. (1842). La democracia en América[1840], 2 tomos. Borda, L. (trad.). París: Librería de don Vicente Salvá.

Torres, C. A. (2001-2002). Obras completas, 3 vols. Bogotá: Instituto Caro y Cuervo.

Velandia, R. (2001). Un siglo de historiografía colombiana: cien años de la Academia Colombiana de Historia. Bogotá: Academia Colombiana de Historia.

Vergara y V., F. J. (1974). Nueva geografía de Colombia escrita por regiones naturales [1888, 1892 y 1901], 3 vols. Bogotá: Banco de la República.

Vergara y V., F. J. (1897). 1818 Guerra de Independencia. Bogotá: Librería Americana.

Vergara y V., F. J. (1906). Capitulos de una historia civil y militar de Colombia, segunda serie. Bogotá: Imprenta Eléctrica.

Vergara y V., F. J. (1907). Tratado de metodología y crítica histórica y elementos de cronología colombiana. Bogotá: Imprenta Eléctrica.

Vergara y V., F. J. 1913 Archivos Nacionales: indice analítico, metódico y descriptivo. Bogotá: Imprenta Nacional de Colombia. 
Vergara y V., J. C. (1952). Don Antonio de Vergara Azcárate y sus descendientes, 2 vols. Madrid: Imprenta de J. Pueyo.

Whitehead, A. N. (1961). Los fines de la educación [1929]. Buenos Aires: Paidós.

\section{VOLÚMENES COLECTIVOS}

Varios. (1975). Historia del arte colombiano, 5 vols. Barney-C., E. (dir.). Bogotá: Salvat.

Varios. (1976). La Nueva Historia de Colombia. Jaramillo A., D. (comp.). Bogotá: Instituto Colombiano de Cultura.

Varios. (1978). Colombia hoy. Arrubla, M. (coord.). Bogotá: Siglo XXI.

Varios. (1978-1980). Manual de historia de Colombia, 3 vols. Jaramillo U., J. (dir.). Bogotá: Instituto Colombiano de Cultura.

Varios. (1987a). Historia de Colombia, 8 vols. Hernández de A., G. (dir.). Bogotá: Salvat.

Varios. (1987b). Historia económica de Colombia. Ocampo, J. A. (ed.). Bogotá: Siglo XXI.

Varios. (1988). La historia de Antioquia. Melo, J. O. (dir.). Bogotá: Presencia.

Varios. (1989). Nueva bistoria de Colombia, 9 vols. Tirado M., Á. (dir.). Bogotá: Planeta.

Varios. (1990-2004). Revista Credencial Historia, 171 entregas. Calderón S., C. (ed.). Bogotá: Credencial.

Varios. (1991-1993). Gran enciclopedia de Colombia, 11 vols. Calderón S., C. (ed. y coord.). Santafé de Bogotá: Círculo de Lectores.

Varios. (1996). Historia de Medellín, 2 vols. Melo, J. O. (ed.). Santafé de Bogotá: Compañía Suramericana de Seguros.

Varios. (2007-2016). Revista Credencial Historia, 114 entregas. Rodríguez, J. C. (ed.). Bogotá: Credencial. 